\title{
A11103089249
}

NATL INST OF STANDARDS \& TECH R.I.C.

(

A11103089249

CE \& TECHNOLOGY:

Symposium for Docume/Documentation of co
CC100.U57 NO.500-15, 1977 C.1 NBS-PUB-C

\section{DOCUMENTATION OF COMPUTER PROGRAMS AND AUTOMATED DATA SYSTEMS}

NBS Special Publication 500-15 U.S. DEPARTMENT OF COMMERCE National Bureau of Standards 


\section{NATIONAL BUREAU OF STANDARDS}

The National Bureau of Standards ${ }^{1}$ was established by an act of Congress March 3, 1901. The Bureau's overall goal is to strengthen and advance the Nation's science and technology and facilitate their effective application for public benefit. To this end, the Bureau conducts research and provides: (1) a basis for the Nation's physical measurement system, (2) scientific and technological services for industry and government, (3) a technical basis for equity in trade, and (4) technical services to promote public safety. The Bureau consists of the Institute for Basic Standards, the Institute for Materials Research, the Institute for Applied Technology, the Institute for Computer Sciences and Technology, the Office for Information Programs, and the Office of Experimental Technology Incentives Program.

THE INSTITUTE FOR BASIC STANDARDS provides the central basis within the United States of a complete and consistent system of physical measurement; coordinates that system with measurement systems of other nations; and furnishes essential services leading to accurate and uniform physical measurements throughout the Nation's scientific community, industry, and commerce. The Institute consists of the Office of Measurement Services, and the following center and divisions:

Applied Mathematics - Electricity - Mechanics - Heat - Optical Physics - Center for Radiation Research — Laboratory Astrophysics ${ }^{2}$ - Cryogenics ${ }^{2}$ - Electromagnetics ${ }^{2}$ - Time and Frequency ${ }^{2}$.

THE INSTITUTE FOR MATERIALS RESEARCH conducts materials research leading to improved methods of measurement, standards, and data on the properties of well-characterized materials needed by industry, commerce, educational institutions, and Government; provides advisory and research services to other Government agencies; and develops, produces, and distributes standard reference materials. The Institute consists of the Office of Standard Reference Materials, the Office of Air and Water Measurement, and the following divisions:

Analytical Chemistry - Polymers - Metallurgy - Inorganic Materials — Reactor Radiation — Physical Chemistry.

THE INSTITUTE FOR APPLIED TECHNOLOGY provides technical services developing and promoting the use of available technology; cooperates with public and private organizations in developing technological standards, codes, and test methods; and provides technical advice services, and information to Government agencies and the public. The Institute consists of the following divisions and centers:

Standards Application and Analysis - Electronic Technology - Center for Consumer Product Technology: Product Systems Analysis; Product Engineering - Center for Building Technology: Structures, Materials, and Safety; Building Environment; Technical Evaluation and Application - Center for Fire Research: Fire Science; Fire Safety Engineering.

THE INSTITUTE FOR COMPUTER SCIENCES AND TECHNOLOGY conducts research and provides technical services designed to aid Government agencies in improving cost effectiveness in the conduct of their programs through the selection, acquisition, and effective utilization of automatic data processing equipment; and serves as the principal focus wthin the executive branch for the development of Federal standards for automatic data processing equipment, techniques, and computer languages. The Institute consist of the following divisions:

\section{Computer Services — Systems and Software - Computer Systems Engineering — Information Technology.}

THE OFFICE OF EXPERIMENTAL TECHNOLOGY INCENTIVES PROGRAM seeks to affect public policy and process to facilitate technological change in the private sector by examining and experimenting with Government policies and practices in order to identify and remove Government-related barriers and to correct inherent market imperfections that impede the innovation process.

THE OFFICE FOR INFORMATION PROGRAMS promotes optimum dissemination and accessibility of scientific information generated within NBS; promotes the development of the National Standard Reference Data System and a system of information analysis centers dealing with the broader aspects of the National Measurement System; provides appropriate services to ensure that the NBS staff has optimum accessibility to the scientific information of the world. The Office consists of the following organizational units:

Office of Standard Reference Data - Office of Information Activities — Office of Technical Publications - Library Office of International Standards - Office of International Relations.

${ }_{1}$ Headquarters and Laboratories at Gaithersburz, Maryland, unless otherwise noted; mailing address Washington, D.C. 20234.

${ }^{2}$ Located at Boulder, Colorado 80302. 


\section{COMPUTER SCIENCE \& TECHNOLOGY:}

\section{Documentation of Computer Programs and Automated Data Systems}

Proceedings of a Symposium

Held at the National Bureau of Standards,

Gaithersburg, MD, October 12, 1976

Edited by:

Mitchell A. Krasny

National Technical Information Services

Springfield, VA 22161

\section{Sponsored by}

Federal Information Processing Standards Task Group 14

(Documentation for Information Processing Systems)

National Bureau of Standards

Washington, D.C. 20234

In conjunction with the

\section{ADP Management Center}

U.S. Civil Service Commission

Washington, D.C. 20415

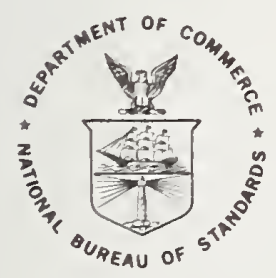

U.S. DEPARTMENT OF COMMERCE, Juanita M. Kreps, Secretary

Dr. Sidney Harman, Under Secretary

Jordan J. Baruch. Assistant Secretary for Science and Technology

NATIONAL BUREAU OF STANDARDS, Ernest Ambler, Acting Director

Issued July 1977 


\section{Library of Congress Cataloging in Publication Data}

Main entry under title:

Documentation of computer programs and automated data systems.

(Computer science \& technology) (NBS special publication; 500-15) Supt. of Docs. no.: Cl3.10:500-15.

1. Electronic data processing documentation-Congresses. I. Krasny, Mitchell A. II. Federal Information Processing Standards Task Group 14 on Documentation for Information Processing Systems. III. United States. ADP Management Training Center, Washington, D.C. IV. Series. V. Series: United States. National Bureau of Standards. Special Publication ; 500-15.

QC100.U57 no. 500-15 [QA76.9.D6] 602'.ls 77-608169 [001.6'425]

\section{National Bureau of Standards Special Publication 500-15}

Nat. Bur. Stand. (U.S.), Spec. Publ. 500-15, 66 pages (July 1977) CODEN: XNBSAV 
This symposium was organized to introduce the Government ADP community to the concepts of when and how to apply the government-wide guidelines of FIPS PUB 38 "Guidelines for Documentation of Computer Programs and Automated Data systems" - in developing both agency standards and operational documentation. The proceedings contain all of the papers presented in the plenary session, and the papers plus summaries of question and answer sessions presented in three parallel sessions for management, operations, and staff attendees.

\section{KEY WORDS}

Automated data systems; computer programs; documentation, documentation content guidelines; FIPS guidelines; software; symposium proceedings. 
The planning, design, development, and implementation of computer programs and automated data systems (software) represent a considerable investment of human and automated resources. To maximize the return on this investment, and to provide for cost-effective operation, revision, and maintenance, sufficient documentation is needed in each stage of the software development life cycle. FIPS PUB 38 was prepared to provide Government-wide guidelines in response to that need. In order to introduce the government ADP community to the concepts of FIPS PUB 38, FIPS Task Group 14 (Documentation for Information Processing standards) organized a symposium to provide attendees with a fuller understanding of when and how to apply these government-wide guidelines in developing agency standards or operational documentation. That symposium is documented in these proceedings.

Because the publication process is already longer than it should have been, the authors have not had an opportunity to review the results of my editing. I accept responsibility for any change in meaning which this process may have inadvertently introduced. My editing was 1 imited to:

Style - I imposed a degree of consistency to different references to the same subject (for example, four different ways of writing "FIPS PUB 38";

Clarity - I tried to untangle some grammatical constructions which, while acceptable in an oral presentation, are cumbersome or confusing on paper;

Space - in a few cases, I shortened sentences here and there to keep a paper from ending with only two or three lines on the past page.

One of the purposes FIPS TG 14 had in mind for this symposium was to open channels for feedback on FIPS PUB 38 from the attendees. Only time can tell how well that purpose was achieved. Meanwhile, FIPS TG 14 is developing guidelines for other document types. Included in the 1 ist, as of this writing, are: Project Request, Project Norebook, Project Development Plan, Post-Installation Evaluation Report, System Development Activity/Task Report, Feasibility Analysis Document, and Cost/Benefit Analysis Document. Readers who are interested in working on any of these projects, or who can suggest additional ones, may contact any TG-14 member, or the office of the Associate Director (of NBS) for ADP Standards, (301) 921-3157.

On behalf of FIPS TG 14, I wish to express appreciation to the speakers and panelists, who contributed so much of their time and effort to this symposium; to the National Bureau of Standards, for administrative and logistical support, which made the symposium run smoothly; and to the Civil Service Commission, which was extremely helpful in the final planning for and announcing of this symposium. Mark Silverman, Roy Young, and I had all the fun of putting it together, while all these others had all the work. Finally, this symposium could not have been successful without the wholehearted support of the nearly 300 attendees, without whom the whole thing would have been pointless. We thank you very much.

On a final, personal note, I wish to thank all the secretaries who typed their bosses' speeches, and got them to me by the deadine. By the time I had edited the first few, I realized that they'd all have to be retyped. My own secretary, Mrs. Karen V. Warmus, has done an outstanding job, and has helped me tremendously in this undertaking.

March 24, 1977

Springfield, Va 22161
Mitche11 A. Krasny, Editor

National Technical Information Service 
ABSTRACT \& KEYWORDS

PREFACE

TABLE OF CONTENTS

INTRODUCTION

Mark Silverman

WELCOME ADDRESS

$M$. Zane Thornton

WHY DOCUMENT?

Theodore D. Puckorius

THE PHILOSOPHY OF FIPS PUB 38 - AN INTRODUCTION

James Gillespie

LIFE CYCLE CONCEPTS AND DOCUMENT TYPES

Roy A. Young

FLEXIBILITY PROVISIONS AND DOCUMENT TYPE SELECTION

Robert R. Hegland

CONTENT GUIDELINES

Thomas $M$. Kurihara

DESCRIPTION OF AFTERNOON SESSIONS

Mark Silverman

SESSION A

US DA APPLICATION MANAGEMENT

Robert $V$. Head

DOCUMENTATION STANDARDS - A MANAGEMENT VIEW Eugene B. Smith

KEY ELEMENTS IN THE ADP SYSTEM DEVELOPMENT PROCESS AT HUD Dr. Marvin Goer

SYNOPSIS OF QUESTIONS AND ANSWERS FROM PARALLEL SESSION A Greg Loss and Tom Kurihara

SESSION B

INTRODUCTION: ADP SYSTEMS, OPERATIONS, AND PROGRAMMER PERSONNEL

Thomas Giammo

PROBLEMS IN USING THE DOCUMENTATION GUIDELINE.

Robert R. Hegland

SYNOPSIS OF QUESTIONS AND ANSWERS FROM PARALLEL SESSION B

Robert A. Mattes and Kenneth Rodey

SESSION C

INTRODUCTION: "STANDARDS, TRAINING, POLICY AND AUDIT PERSONNEL" 50

Harris $G$. Reiche

FIPS PUB 38 - IMPLEMENTATION PHILOSOPHY IN HEW

Joseph J. Strnad

THE ROLE OF THE AUDITORS IN THE DEVELOPMENT \& EVALUATION OF

AUTOMATED SYSTEMS

Phillip L. Morrison

SYMOPSIS OF QUESTIONS AND ANSWERS FROM PARALLEL SESSION C

Fred J. Cole and Edie Lasner

FIPS TASK GROUP 14 MEMBERSHIP \& SYMPOSIUM PLANNING COMMITTEF,

BIBLIOGRAPHIC DATA SHEET 



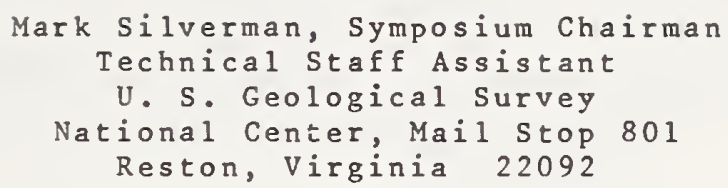

Welcome to the Symposium for Documentation of Computer Programs and Automated Data Systems, which is being held to afford attendees a better understanding of FIPS PUB 38. FIPS Task Group 14 developed FIPS PUB 38 as a set of guidelines for Government-wide use to meet the need for adequate and consistent documentation during the development stage of a software system's life cycle.

The life cycle of a software system includes the stages of planning, design, development, implementation, and maintenance. Each of these stages may require a substantial investment in time and other resources.

This symposium should help attendees apply the guidelines in FIfs pub 38 to reduce costs significantly. We hope you will find these guidelines helpful both in the development of agency standards for software documentation and in documenting computer programs and automated data systems.

And now, I am pleased to present Mr. M. Zane Thornton, the Deputy Director of the Institute for Computer Sciences and Technology, the National Bureau of Standards. Mr. Thornton will provide some background on the FIPS program and introduce our distinguished Keynote speaker. 


\section{Zane Thornton \\ Deputy Director \\ Institute for Computer Sciences and Technology \\ National Bureau of Standards \\ Washington, D. C. 20234}

Good morning, Ladies and Gentlemen. I am pleased to welcome you to the National Bureau of $\mathrm{Standards}$ and this symposium on the Documentation of Computer Programs and Automated Data Systems. Before I introduce our keynote speaker, let me briefly review the NBS ADP Standards program and the Federal Information Processing Standards (or FIPS) activities which produced the documentation guidelines which are the subject of today's meeting.

Since enactment of Public Law 89-306 (Brooks Act), the National Bureau of Standards has had a leadership role in the management of activities within the Federal Government relating to the development and maintenance of uniform Federal automatic data processing standards. The continuing objectives of the NBS ADP Standards Program are to facilitate the interchange and sharing of data, programs, and equipment by Federal agencies; to improve performance and quality of ADP products and services developed by or acquired by Federal agencies; and to make Government and industry aware of the need for standards to achieve compatibility and enhance the effective utilization of ADP products and services in the preparation and delivery of public services.

The Federal Information Processing standards program sets mandatory $s$ tandards for the Federal ADP-community. In carrying out this program, NBS has maintained close cooperation with the voluntary standards activities of the American National Standards Institute (ANSI) and the International Organization for Standardization (ISO). NBS, in its standards management role, is responsible for assuring Federal participation in the development of ANSI and ISO voluntary standards, for considering them for adoption as Federal standards in those cases where they meet the requirements of the Federal Government, or for initiating independent development actions in cases where ANSI and ISO efforts do not exist, or are too slow.

The NBS FIPS program identifies those areas in which ADP standards are needed, pursues their development, and promulgates the completed standards through Federal Information Processing Standards Publication (FIPS PUBS). Presently there are fourteen active FIPS task groups with over 350 professional participants from Government and industry, addressing such areas as programming languages, data codes, security and privacy, network protocols, and documentation. To date, 44 standards, guidelines, and information documents have been developed and published by NBS in the FIPS PUB series. The current standards effort addresses four major areas: (1) standards that provide for the effective interchange and sharing of data, programs, and equipment, (2) standards to increase the performance and assure quality control of ADP products and services; (3) standards that facilitate the transfer and use of computer technology through effective man-machine interfaces; and (4) standards to provide for the safety and security of personnel, equipment, and data. Priorities are given those standardization development efforts which have the most need and highest potential benefit.

In June 1974, in a letter from the Director of NBS to the Director of the General Government Division of the General Accounting Office, Documentation was cited as one of the highest priority subjects in the Federal ADP Standards Program. In October 1974, the Comptroller General of the U.S. in a report to Congress entitled "Improvement Needed in Documenting Federal Computer Systems" affirmed that "Government standards are not available to 
assist Federal managers in deciding what type of documentation to prepare, how much to prepare, and when and how to prepare it." The report noted that "although good documentation does not insure successful computer op,erations, inadequate documentation can

- increase the cost of Federal operations,
- weaken management control of ADP systems,
o contribute to loss of funds and assets, and
- limit the potential for sharing programs."

FIPS Task Group 14, "Documentation for Information Processing Systems", was established in March 1973, and charged with developing standards and guidelines for the documentation of individual computer programs and automated data systems. This task group is composed of representatives of more than twenty Federal agencies. FIPS PUB 38 is one of the products of this group. Using available guidelines from various Federal, commercial, and academic organizations as points of departure, the group selected the best features of the best of these, and made them generally applicable to Federal computer installations. FIPS PUB 38, which you have as part of your registration packet, has been extensively reviewed, revised and coordinated among the Federal and non-Federal ADP community.

These guidelines for Documentation of Computer Programs and Automated Data Systems have been prepared in response to the need for documentation to support the effective management of ADP resources, and to facilitate the interchange of information about computer software. The objectives are to:

- Provide managers with technical documents to review at significant development milestones,

- Record technical information to allow later use and modification of software,

- Facilitate understanding among managers, developers, programmers, and users of software,

- Increase the potential for transferability and sharing of software, and

- Provide a basis for auditability of software.

Your study of these guidelines today should help achieve these goals.

At this point, I'd like to thank the ADP Management Center of the U. S. Civil Service Commission, for jointly sponsoring this symposium with us.

Now it gives me great pleasure to introduce our featured speaker, Mr. Theodore D. Puckorius.

Theodore D. Puckorius was appointed Commissioner of the General Services Administration's Autorated Data and Telecommunications Service (ADTS) on May 19, 1975. As ADTS Commissioner, he heads an organization which is responsible for centralized management of general purpose data processing and support services for all Federal agencies, as well as management and operations of the civilian government's telecommunications system. ADTS' operations include overall procurement responsibility for nearly $\$ 800$ million worth of ADP hardware, software, services, and maintenance annually; coordination, consolidation, and collocation of Federal requirements to allow maximum utilization and sharing of government computer resources; operation of three Federal Data Processing Centers which provide a full 
range of data processing services for individual agencies; an inter-active timesharing computer system which permits remote access service nationwide; and a comprehensive, multi-million dollar communications network which serves Federal agencies across the nation through some one million phones, over 10 million miles of circuitry, and thousands of data transmission devices.

Prior to his appointment as ADTS Commissioner, he was Vice President and Manaing Officer of the Government Services Division for Lester B. Knight and Associates, Inc. in Chicago, Illinois, and Washington, D. C. Lester B. Knight is a Chicago-based firm specializing in management consulting and architectural/engineering services.

From 1965 until 1971, he served in key management positions with Booz, Allen and Hamilton, Inc., a Chicago consulting firm. Previously, he held increasingly responsible positions with North American Aviation in Columbus, Ohio; AVCO Electronics and Ordnance Division in Cincinnati, Ohio; Hertz Corporation in Chicago, Illinois; and the Pillsbury Company in Minneapolis, Minnesota.

Mr. Puckorius was born in Chicago on April 7, 1930. He attended DePaul University and received a Bachelor of Science degree with honors from the University of Illinois. He has done graduate work in financial management and production managent at the University of Illinois and Ohio State University. He is a veteran of the United States Air Force.

Mr. Puckorius will discuss why we have documentation standards and guidelines. His talk is titled: "Why Document?" 


\section{Commissioner, Automated Data and Telecommunications Service General Services Administration 18 th \& F Streets, NW, Room 3240 Washington, D. C. 20405}

of increasing concern in the past few years has been technology transfer which implies the communication of some technological advancement from the innovators to those who need the information. Technological developments follow one another at a furious pace. So rapid is the progress that the pioneers in one area run the risk of finding that what they are perfecting at great expense and great effort is also being perfected in another location, likewise with great expense and great effort. One of the particular areas of technology transfer which has been of great interest is that of computer software, and development of such software represents a significant portion of the Federal ADP Budget.

Fiscal Year 1975 Federal ADP Inventory shows the total annul cost for ADP in the government to be approximately $\$ 3.1$ billion. If you take from this figure the $\$ 850 \mathrm{million}$ spent for hardware purchase and rental, supplies and site preparation, you will see that a total of $\$ 2.25$ billion was spent on software and related personnel costs alone. That is approximately three times the amount of all other ADP related costs combined. As FIPS PUB 38 states in the introduction: "To maximize the return on this investment, and te orovide for cost-effective operation, revision and maintenance, sufficient documentation is needed at each stage of the software development lifecycle".

Documentation is essential to the effective development, implementation, modification, operation, and utilization of any system. Yet this is a notoriously weak area in the ADP industry--and one in which there are few industry-wide standards or guidelines. Books on programming and documentation techniques have been published almost since the first program written in machine language; and large organizations and institutions have established internal standardization requirements. Nevertheless, no one single cohesive agreement on documentation has been reached or accepted for widespread usage. Likewise, funding constraints, tight scheduling and general programmer distaste for writing--have generally relegated program documentation to the lowest priority. As a result, the GAO Study on Automated Decision Making indicates there is much room for improvement. Existing standards are not being complied with.

Documentation could be and is used by a variety of ADP-industry people during the initiation, development and operation phases of the software life cycle.

systems analysts require documentation in planning new systems

programmers need documentation when writing instructions to implement the analysts' plans

management needs some type of documentation when monitoring and controlling system development and operations.

auditors need documentation in evaluating system reliability and in advising management of possible system shortcomings.

The documentation used by these people can be categorized into four major areas of application: 1) user, 2) system, 3) program, and 4) operations. 
There are many levels of users of software systems with differing information needs--from top level management, through operating management, to the equipment operator. For a software system to be used productively, instructions and aids to understanding for all levels of intended users must be provided by system documentation.

How is this rather 1 imited documentation employed by the user?

The input-layout and completion instructions enable the user to complete specified documents for input to the system. The output report definitions and explanations gives the user the basis for understanding and interpreting the output. Should a problem develop with the input, the error correction procedures provide the user the means for re-inputting corrections.

In many data processing applications there is no user documentation at all. Input documents are considered to be self-explanatory--as are the reports generated by the system. To correct errors-either an error code is issued--or it is left up to the user to figure out his own mistake.

Why Document?

Why, indeed!! Most data processing systems cost substantial amounts of money, manpower, equipment, and time to develop. They were developed for utilization by user departments. But, can the user make best use of the syotem's resources and potential with scant--or worse yet--no documentation?

For effective utilization of any system, the user must understand the purpose of the syotem, how the system works--functionally--and what the system's capabilities are. The user must understand how the capabilities can be most effectively utilized.

System documentation in most data processing installations ranks as the lowest priority in the already low priority that documentation holds. It is therefore usually non-existent.

System documentation should exist to specify for the analysts and programmers- the requirements--the operating, environment--the design characteristics-- and programspecifications for a system.

Documentation should exist, but, all too often, much unnecessary work and wasted time is encountered due to the absence of documented definitions or detailed specifications. Many changes must be made due to poor communication and poor documentation of the users' needs.

Escential to the development of an efficient and effective system are concrete and well defined job objectives and specifications. The system analyst (or system designer) cannot effectively accomplish his end, and supply the programing staff with a workable detail design if the work has had to come from inadequately defined objectives.

The problems arising from a lack of (or poor) system documentation magnify themselves as the system development progresses. Each step in the growth of a system is dependent upon the accuracy and effectiveness of the work and documentation of the preceding steps.

During post-implementation review, the system documentation is the only valid means of comparison between the use-specifications and the end results. Without it, one must rely upon the "best recollections" of individuals involved. Hopefully, those individuals are still available to quety. When changes, modifications, or maintenance becomes necessary, the syster andysts (designers) and/or programmers must rely upon their experience with the system (if any) or piece together program documentation (if any), unless system documentation is available. This makes the 
analyst/programmers' jobs not only difficult, but expensive--as it requires substantially more time and work on their part to understand the current system--in order to apply changes. Systems documentation is important because it saves both time and money. Similarly, the programmer cannot design and program efficiently to meet the user needs without accurate and detailed specifications.

Equally important to both the maintenance and the operations staff is the programmer's documentation. Program documentation provides the maintenance programmers with the knowledge essential for effective debugging and implementation of enhancements and modifications. often the person maintaining a program is not the author. Complete program documentation is less costly in man hours than having maintenance programmers wade through source codes to obtain the understanding of the program they need.

Documentation provides the operations personnel with the specifications and requirements essential to planning hardware/software needs.

Operations personnel can also lend valuable expertise in terms of hardware/software utilization, scheduling requirements, and input/ output handling in the system design stage of a process. Cooperation between programing and operations can prove a valuable asset to any system development.

\section{Why Document?}

Documentation provides the means for the greatest and most efficient utilization of the system by the user.

Documentation provides the means for careful, well-planned design and integration of the system.

Documentation provides the maintenance programmers with the knowledge essential for effective debugging and implementation of enhancements and modifications.

Documentation provides the operations personnel with the specifications and requirements essential to planning hardware/software needs and scheduling computer utilization.

Further, documentation provides for successful and cost effective sharing. The recently established Software Exchange program by ADTs provides for the sharing of computer programs developed by one organization for use by another organization on a similar task. Documentation of programs and systems must be adequate to enable the secondary user to understand the program capabilities, peculiarities, and limits in order to determine whether the program meets the needs stipulated. Secondary users also need good documentation to understand how to run the program and to make any necessary modifications.

In addition to the Software Exchange program, GSA has recently established a project to obtain documentation Software for government-wide use under a requirements-type contract. As a follow-on to a 1974 GAO Study, wherein GAO canvassed 70-different ADP installations and concluded that there exists a need for better documentation in the Federal government; and in keeping with the stated objectives of FIPS PUB 38; GSA is taking an active role in software management. Through this current procurement, we plan to promote better documentation in the Federal government and encourage the use of a technically valid automated documentation system. The expected benefits include:

more emphasis on good documentation, with the result that Federal ADP Managers will become cognizant of this need. 
In the long term, this emphasis should result in develop, ment by industry of more efficient and economical software for government use

- better documentation of government systems which will aid in application program development and program maintenance

- achievement of volume discounts through centralized bulk procurement and elimination of procurement costs on an agency-by-agency basis.

Why Document?

Because it is essential to the effective development, implementation, modification, operation and utilization of any system. 


\author{
James Gillespie \\ Chief of Naval Operations (OP-914D) \\ Department of the Navy \\ Washington, D. C. 20350
}

My part in this program is very simple, and very pleasurable. First, I wish to express the appreciation of FIPS Task Group 14 to Mr. Thornton and Mr. Puckorius for taking the time to participate in this ymposium.

Second, I want to introduce the next three speakers, who will describe the different aspects of the philosophy behind FIPS PUB 38. Roy Young will describe the life cycle concept and the document types which occur at each stage in that life cycle. Bob Hegland will describe the flexibility that each agency has, both in developing in-house standards or guidelines, and when selecting document types in any given application. Finally, Tom Kurihara will provide a brief description of the content guidelines for each of the ten document types.

After Tom's presentation, Mark Silverman, who chaired the symposium planning committee, will describe the rest of our program. It's a real pleasure for me to be here today. I hope that by the time it's over, you'll feel the sane way. 


\title{
LIFE CYCLE CONCEPTS AND DOCUMENT TYPES
}

\author{
Roy A. Young \\ U.S. Department of Health, Education, \& Welfare \\ 330 Independence Avenue, SW \\ Washington, D. C. 20201
}

A good system of life cycle documentation not only specifies how information is to be recorded, but also when it is to be recorded. It has long been established that poor or inadequate communication between personnel is a major problem, and it always starts at the initiation phase of a project, and then continues until the system is terminated.

If documentation is done concurrently with task development, the completion of each task is signified by the availability of the finalized documents. A review of the completed documentation during development and after implementation phases provides the opportunity for assessing progress, and it can point out problem areas between scheduled and actual dates.

When newly proposed systems are to interface with an existing system, it is vital to review the interaction between the two systems. This can only be achieved if the previously designed system is adequately documented.

The first exhibit (Exhibit A) is easy to identify with, because documentation, in many respects, says about as much as this exhibit. We all have reviewed this type of documentation at one time or another in our careers. We hope that after the FIPS PUB 38 symposium today, we can all go back better prepared, so we don't leave those who come in contact with our documentation frustrated because it lacks the technical explanations and clarity to be understood.

Many of us, as managers without documentation standards and policy guidelines, have been confronted with the individual who says, "You do it your way and I'll do it mine." (Exhibit B) Their arguments are that their documentation is adequate to do their job. However, we all know that for a new employee given a new project, the documentation in most cases is not adequate. It is easy to understand the programmer's feelings when it comes to documentation after the program is operational. But in order to ensure the continued success of the program in a production environment, it must be capable of being maintained. Good documentation is the only answer. As has been pointed out by. earlier speakers, "It pays to document." Documentation is the result of hard work by managers and their staffs (Exhibit C). How many times have you come head-to-head with the problem of documentation? The manager says, "Hey! Your documentation is not complete." The programmer planned on bringing it up to date, but has several excuses as to why he hasn't documented it. As a manager, we have a responsibility to see that documentation is kept current with development and finalized upon implementation.

The delicate position the ADP manager is in when it comes to documentation is pointed out in Exhibit D. As managers, you are constantly being badgered by your staff about what is adequate documentation. If you allow substandard documentation to occur, eventually the user or your boss will be all over you like a tiger. As managers, we know that documentation standards are necessary to stay out of trouble. We must enforce documentation standards or suffer the consequences.

The project manager (Exhibit E) has the ultimate responsibility for documentation. He is the one who must sign off on the system when it is ready for implementation. He must determine whether the documentation is adequate, because he must satisfy the requirement that it will support programming maintenance functions by other programmers. 
When we talk about life cycle concepts, we mean from inception of a new program or system until its discontinuance. The definition of the documentation elements of the software life cycle (Exhibit $F$ ), as it pertains to FIPS PUB 38 is as follows:

PHASES. While terminology used to describe the phases is arbitrary, it provides a convenient framework within which the development of software may be discussed.

Initiation. During the Initiation Phase, the objectives and general definition of the requirements for the software are established. Feasibility studies, cost-benefit analyses, and the documentation prepared within this phase are determined by agency procedures and practices.

Development. During the Development Phase, the requirements for the software are determined and the software is then defined, specified, programmed, and tested. Documentation is prepared within this phase to provide an adequate record of the technical information developed.

Operation. During the Operation Phase, the software is maintained, evaluated, and changed as additional requirements are identified.

STAGES. While the terminology used to describe the stages is arbitrary, it provides a convenient framework within which the development of the ten document types may be discussed. It is recognized that not all of the document types are required to document software in every case, and that in some cases, the various document types may need to be combined.

Definition. During the definition stage, the requirements for the software and documentation are determined. The Functional Requirements Document and the Data Requirements Document may be prepared.

Design. During the design stage, the design alternatives, specific requirements, and functions to be performed are analyzed and a design is specified. Documents which may be prepared include the System/Subsystem Specification, Program Specifications, Data Base Specification, and Test Plan.

Programing. During the programming stage, the software is coded and debugged. Documents which may be prepared during this stage include the Users Manual, Operations Manual, Program Maintenance Manual, and Test Plan.

Test. During the test stage, the software is tested and related documentation reviewed. The software and documentation are evaluated in terms of readiness for implementation. The Test Analysis Report may be prepared.

DOCUMENT TYPES. The purpose of each of the ten document types is defined in the following paragraphs.

Functional Requirements Document. The purpose of the Functional Requirements Document is to provide a basis for the mutual understanding between users and designers of the initial definition of the software, including the requirements, operating environment, and development plan.

Data Requirements Document. The purpose of the Data Requirements Document is to provide, during the definition stage of software development, a data description and technical information about data collection requirements.

System/Subsystem. Specification. The purpose of the system/subsystem specification is to specify for analysts and programmers the requirements, operating environment, design characteristics, and program specifications (if desired) for a system or subsystem. 
Program Specification. The purpose of the Program Specification is to specify for programmers the requirements, operating environment, and design characteristics of a computer program.

Data Base Specification. The purpose of the Data Base Specification is to specify the identification, logical characteristics, and physical characteristics of a particular data base.

User's Manual. The purpose of the User's Manual is to describe sufficiently the functions performed by the software in non-ADP terminology, such that the user organization can determine its applicability and when and how to use it. It should serve as a reference document for preparation of input data and parameters and for interpretation of results.

Operations Manual. The purpose of the Operations Manual is to provide computer operating personnel with a description of the software and of the operational environment in which the software should be run.

Program Maintenance Manual. The purpose of the Program Maintenance Manual is to provide the maintenance programmer with the information necessary to understand the programs, their operating environment, and their maintenance procedures.

Test Plan. The purpose of the Test Plan is to provide a plan for the testing of software; detailed specifications, descriptions, and procedures for all tests; and test data reduction and evaluation criteria.

Test Analysis Report. The purpose of the Test Analysis Report is to document the test analysis results and findings, present the demonstrated capabilities and deficiencies for review, and provide a basis for preparing a statement of software readiness for implementation. 
"I believe you understand what you think I said but I'm not sure you realize that what you heard is not what I meant." 


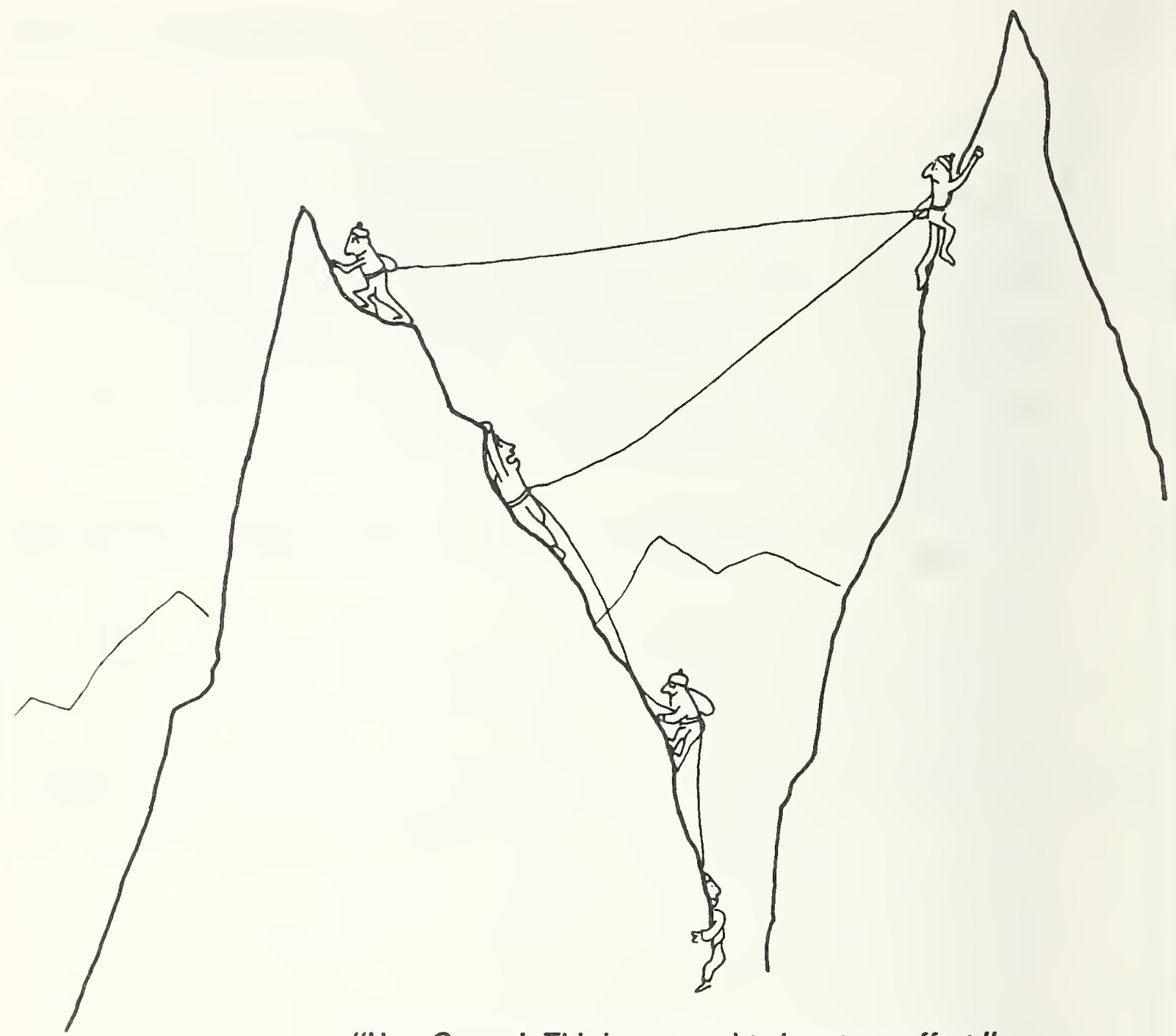

"Hey, George! This is supposed to be a team effort." 


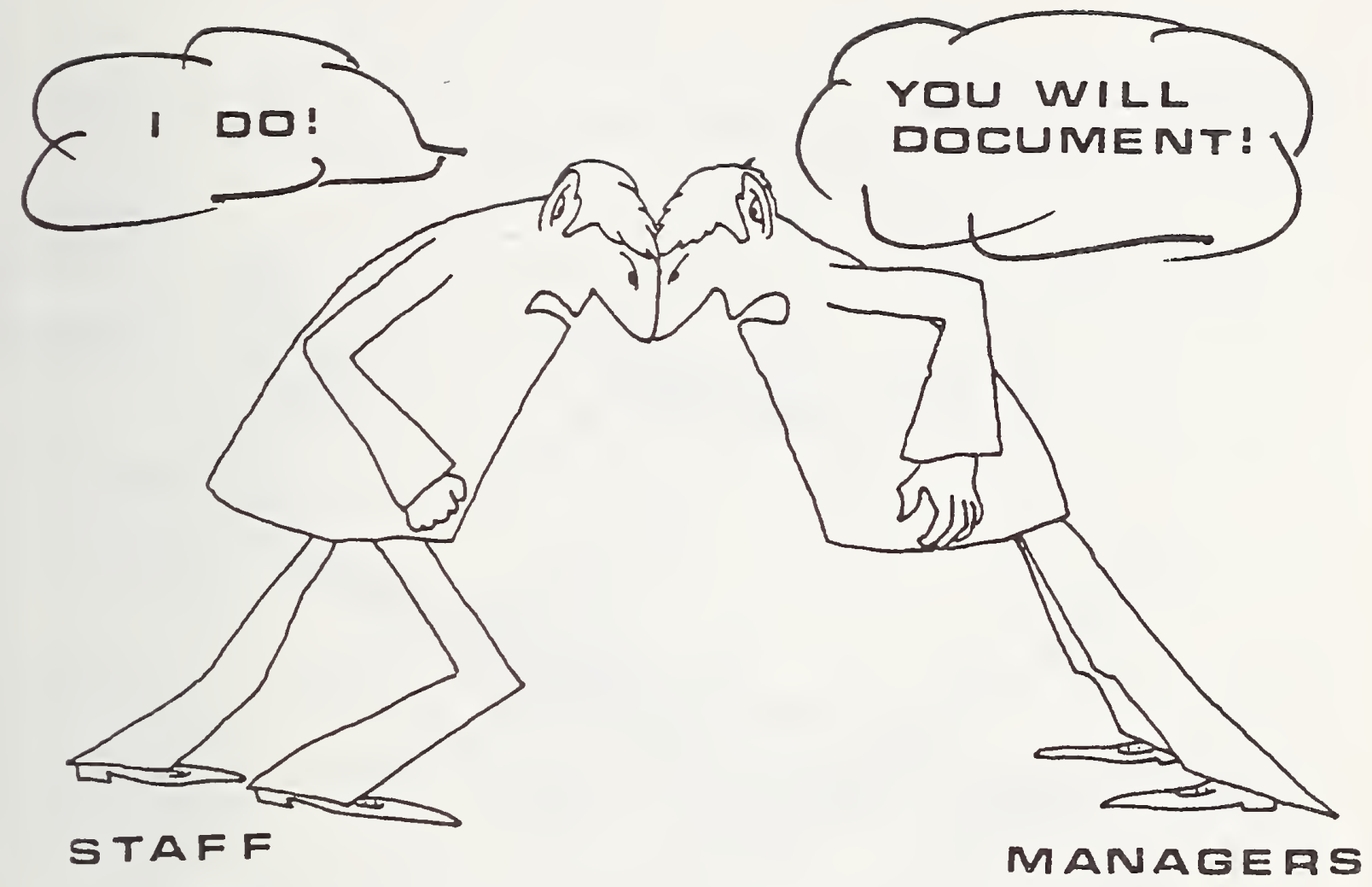

EXHIBIT C 


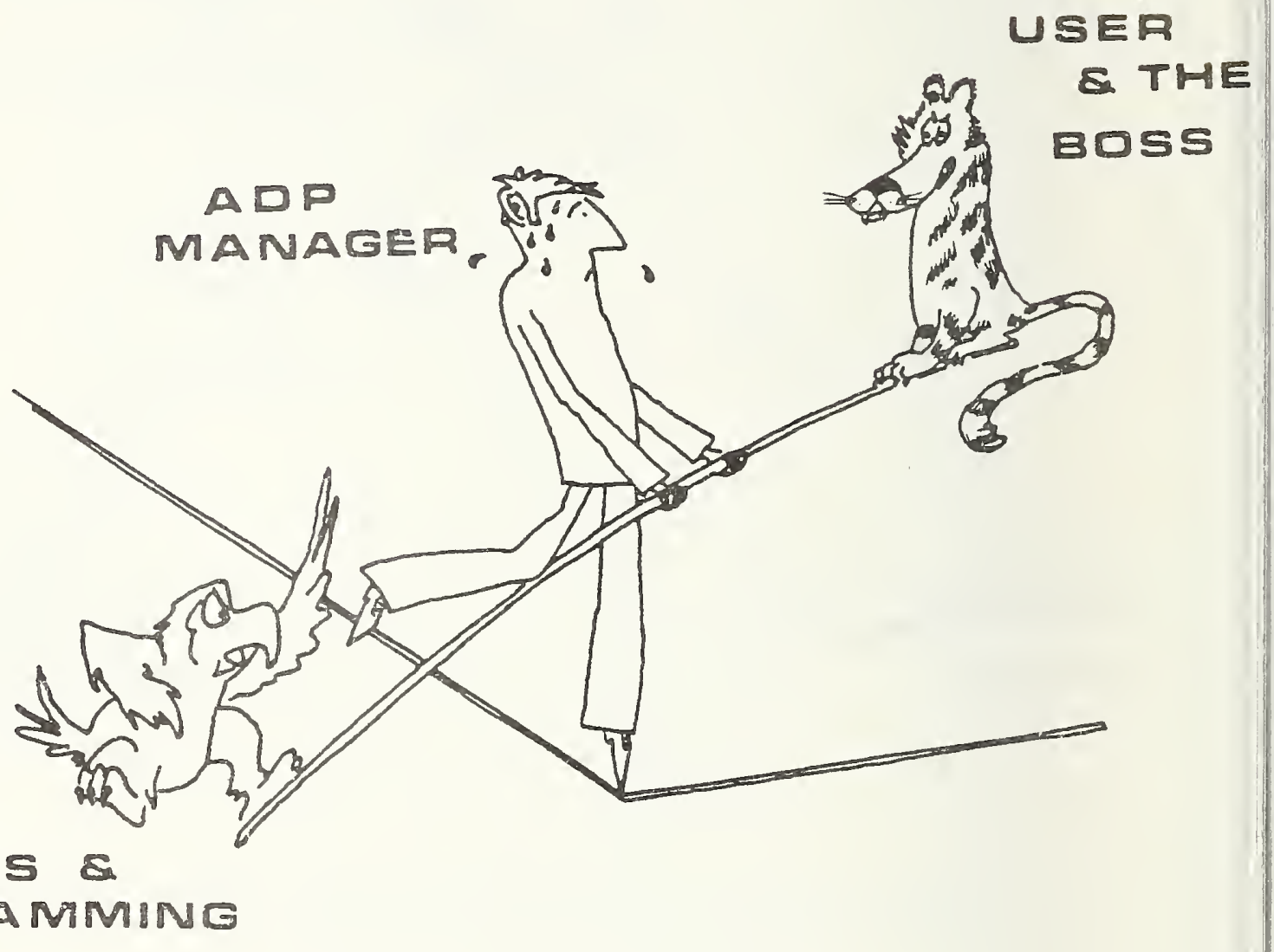

EXHIBIT D 


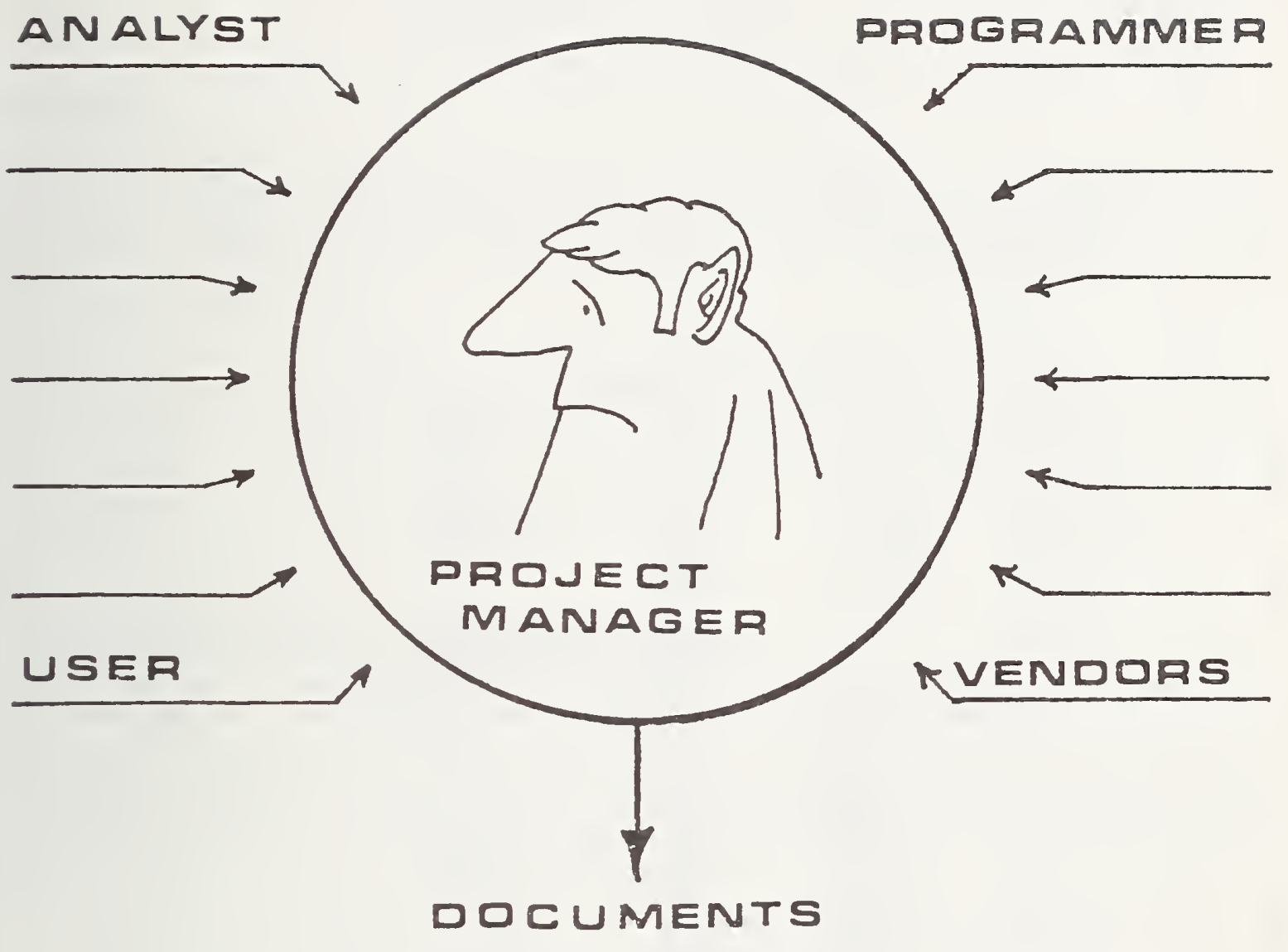

EXHIBIT E 


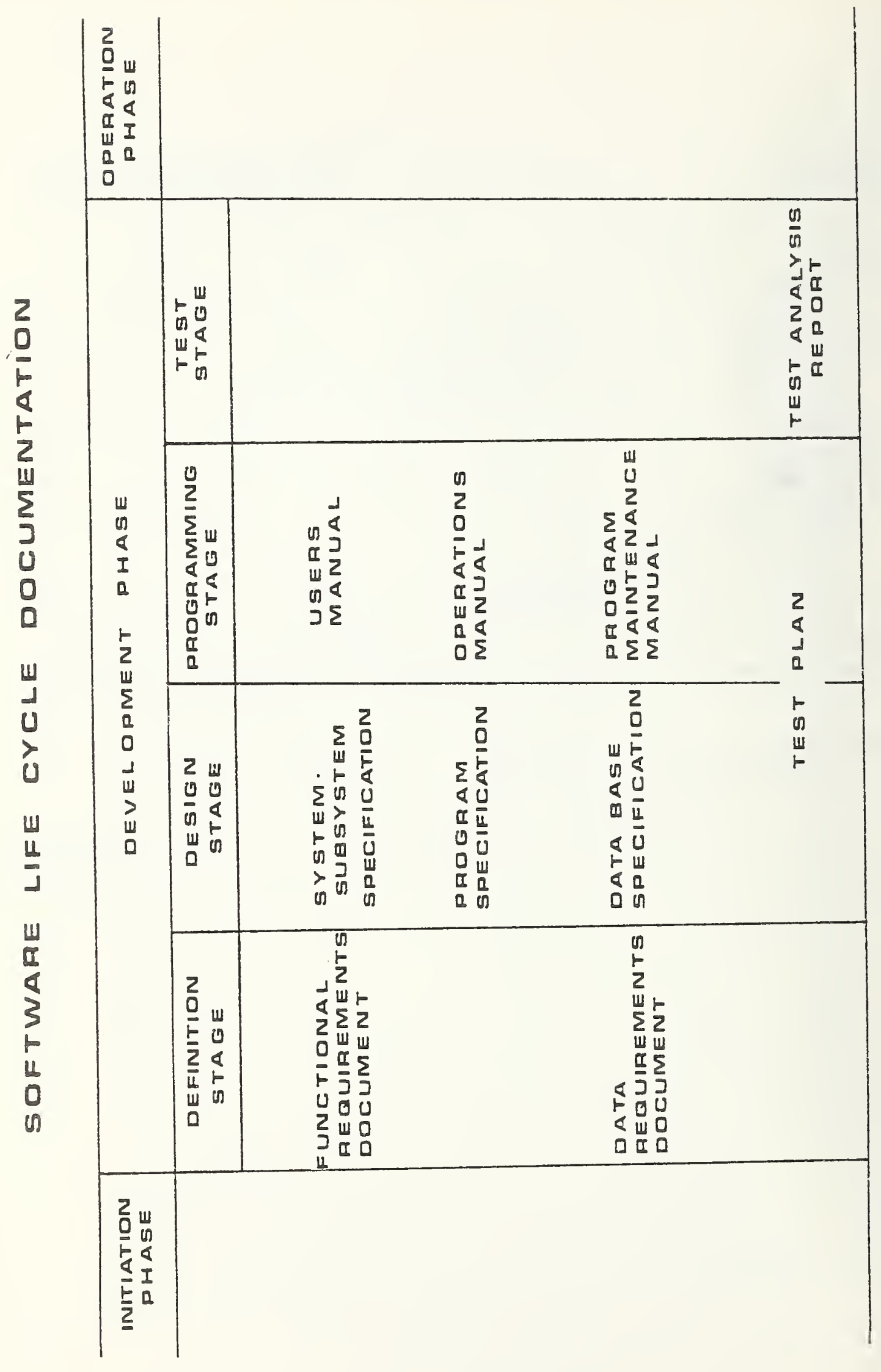




\author{
Robert R. Hegland * \\ Naval Command Systems Support Activity \\ (Code 70.3) \\ Washington Navy Yard \\ Washington, D. C. 20374
}

\title{
INTRODUCTION
}

Most standards and guidelines are not self-implementing. To be most effective, they need to be analyzed by a central office to establish the policies and procedures to implement them in a particular department or agency. The central office must establish the responsibilities and implementation procedures that will make the standard or guideline most useful to its organization.

Discussed herein are those policies and procedures that a central office should consider in implementing the FIPS Documentation Guidelines. The authors of the documents that are discussed in the Documentation Guidelines should be familiar both with the policies and procedures that are established and the flexibility provisions contained in FIPS PUB 38 . Anyone can prepare reams of documentation but it takes some thought and understanding to produce useful documentation.

\section{FLEXIBILITY PROVISIONS}

\section{USING SPECIFIED SECTIONS AND PARAGRAPHS}

The Guidelines provide ten different document types, each of which has several sections. Each section has numbered and titled paragraphs within it. There is some flexibility in using these paragraph numbers and titles. Authors are encouraged to try to use them as they are structured in the Guidelines, since a great deal of time went into developing them. Also, much of the Guidelines is based on a documentation system that has been used and modified over a number of years, and the sequence is essentially the same as is used in that documentation system.

- There is the provision within the Guidelines to add specific program and file names to some of the paragraphs.

- If the author or the central office determines that additional paragraphs or sections are needed, it is suggested that paragraphs be added at the end of a section and sections be added at the end of the document type.

- Sections and paragraphs can also be deleted when they are not applicable to documenting a particular system. This can be done in two ways: by simply omitting them, or by including a short description of why no detailed information is included. An example of this is a paragraph in the Guideline that deals with security. If the system is not classified, there is no need to include a paragraph that explains the security provisions for protecting the system and its data. In either case, the integrity of the Section and Paragraph numbers and titles can be preserved.

\section{AUDIENCES AND FUNCTIONS}

Another provision of flexibility that needs to be recognized is that each of the doctment types is designed for a particular audience and a particular function. This concept is very important because of the great variety of organizational structures that we find in data processing in the various government departments. A given computer program may be used in one organization by only one person, who acts as the user, computer operator, and maintenance programmer. In another organization, there may be three separate people serving those functions for that program. The Guidelines is intended to be independent of organizational structure, so that it can be 
used in both situations. Since there are at least three different functions being performed in each situation, the three different documents should be prepared-one each addressing the function of the user, the computer operator, and the maintenance programmer. The function being performed, rather than the individual looking for the information, determines which document is referenced.

\section{USE OF FORMS}

Another provision of the Guidelines is to allow (and encourage) the use of existing forms in preparing your documentation. There are no forms specified in the Guidelines as being mandatory for documenting a program, since the format of such forms changes so much from one organization to another, and since there are elements on some forms that change depending on the particular hardware and operating system you have. It is suggested, however, that your forms be referenced from the paragraphs that are in the Guidelines, so that the basic structure of the document types can still be used, regardless of the forms that you may be using.

4. USE OF FLOWCHARTS AND LISTINGS

Whether or not to include flowcharts and listings in your documentation is another area where there should be a policy established. Certainly, the maintenance programmer should have access to these, but there is some question as to whether they need to be included and printed in a document. It usually is adequate to have them on file, rather than to have them printed in a formal document.

\section{SUPPLEMENTING THE DOCUMENT TYPES}

There are several other items, in addition to the flowchart and listings, that can be used to supplement the document types. These are useful to remember and use, since the documentation needs to be thought of in a hierarchical structure. The source code is the most detailed level of documentation; the Program Maintenance Manual is the next most detailed, but should not be thought of as taking the place of, or being as detailed as, the source program listing. The source code can serve this function particularly well if it is well commented. Another supplement can be the output of an automated flowchart program. It would seem to be unnecessary to have a printed document of program flowcharts if an automated flowchart package is available to printout a flowchart whenever it may be needed.

The output of a Data Element Library also can be used to reduce the amount of typed, formal documentation. This output could either be included in the Document or referred to from the document.

\section{OTHER DOCUMENT TYPES}

To have a complete documentation system, you may want to establish some other document types, such as a technical report or technical note--that can be used to contain supplements studies, or catalogs, etc.

\section{COMBINING DOCUMENT TYPES}

Some document types can be combined, in some instances. Those that have most frequently been combined are: Users Manual, Operations Manual, and Program Maintenance Manual, to form a Project Manual; several Program specifications, to form a Subsystem specification; and several subsystem specifications, to form a System Specification. This technique may be particularly useful on small projects, but must be used with some care. After all, each document type is intended for a different audience and may, therefore, have a different distribution. Additionally, the different documents will almost surely be completed at different times, so a combined document cannot be published until the last "piece" is finished.

In deciding what document types should be produced for a particular project, there are two different approaches presented in the Guidelines. Your 
organization may want to adopt one or the other, it may want to change some of the factors in one before adopting it, or it may leave that decision to the project leader.

1. COST/USAGE THRESHOLD CRITERIA

Figure 2 in FIPS PUB 38 presents a technique based on the anticipated cost or use of the project to determine the document types that need to be produced.

2. PROJECT COMPLEXITY

Figure 4 in FIPS PUB 38 shows a chart with twelve "complexity factors", each of which can be assigned a weight or "value" between 1 and 5 . When the values are added together, the overall complexity total can be applied to Figure 3 in the Guidelines, to determine what document types are needed for a project of that complexity.

There are some overriding considerations that should be analyzed in deciding which document types will be produced, such as whether a contractor will be involved in the project, whether you are automating a previously manual function, and whether you will be working with an integrated data base.

\section{MANAGEMENT CONSIDERATIONS}

A. DOCUMENTATION PLAN

One of the first things that should be done during project development is to prepare a Documentation Plan to determine what documents will be produced during the project. Other items that should be considered in this plan are:

- Approximate size (or range) of each document.

- Portions of each document that are and are not needed.

- Level of detail of each document.

- Dates when portions of the documents will be available for management review.

\section{B. REDUNDANCY}

In applying the various flexibility criteria, the question of redundancy needs to be clearly understood by the central office and the authors of the documents. There are three kinds of redundancy that have been included intentionally in the document types:

- Stand Alone. The first section of each document contains information on the background of the overall project, to set a frame of reference for the reader.

- Apparent. Many documents appear to call for the same information. The information that is provided, however, may be different, because it is intended for different audiences.

- Evolutionary. There also appears to be some redundancy between document types; it provides programmers the opportunity to document changes that have taken place since prior documentation was produced.

\section{CONCLUSION}

This has been a brief summary of the different flexibility provisions in the Documentation Guidelines. There are many factors that need to be understood before the maximum benefit can be derived from it. The Guidelines is not "self-implementing", and must have the involvement of, and support from, a central office if it is to be used effectively.

* The views expressed herein are those of the author and do not necessarily represent policy of the Department of the Navy or of any naval activity. 
Thomas M. Kurihara

Technical Resources Staff

Data Systems Division

Agricultural Stabilization and Conservation Service

U. S. Department of Agriculture

P. 0 . Box 2415

Washington, D. C. 20013

\section{PURPOSE}

The, purpose of my portion of the Philosophy of FIPS PUB 38 is to describe briefly Part 3, the Content Guidelines. The Content Guidelines in FIPS PUB 38 serves to provide managers of development projects with a guide to follow in prescribing and reviewing project documentation, and writers of documents with content guidelines.

Part 3 of FIPS PUB 38 out 1 ines and describes the content guidelines for ten document types that could be prepared during the software development phase. Before addressing the content guidelines for each of the document type, we must keep in mind the purpose of documentation. These content guidelines were prepared to provide a vehicle for communication between the user and development groups. Each document type is intended to be written for and used by, a specified audience.

\section{AUDIENCES}

The audience (or intended reader) may be an individual or a group of individuals. In the development of automated data systems and computer programs, there are, in general, two audiences: the user group and the development group. The user group provides data inputs, uses the outputs, states the requirements for the development effort, and assumes responsibility for acceptance and use of the system. The development group performs the design, programming, and test functions.

We recognize that your work environment and individual manager's requirements will vary. Regardless, it must be emphasized that when each document type is written, the audience, and its function, should be identified and understood. Consideration should be given to audience knowledge and experience, writing style, terminology, and anount of detail.

Elaborating on Bob's description of functions, let's look at the specific "management" audiences. I will call the first "Approval Management". Their function is to make decisions concerning the project based on its contribution to overall organization objectives.

"Development Management" is interested in the amount of change that must be anticipated; the completeness of user requirements; complexity; mode of operation; available resources; and system life. Their function is to develop a set of technical specifications for the final product, from which program code is prepared and tested. These specifications are translated from functional descriptions stating user requirements.

"User Management" is concerned with improved efficiency and effectiveness; better information for decisions; training; and internal procedures. Their function is to review the development of the system, use the developed systems, identify performance and acceptance criteria, and train user personne 1 .

The developers are concerned with product performance, correct and complete specifications, and completing the project on time. The users, on the other 
hand, are concerned with furnishing data, changing procedures to fit the new system, and understanding how the new system will affect their everyday functions.

Therefore, with an understanding of who the audiences are, the writers of documentation should be guided by the content guidelines contained in FIPS PUB 38. The following comments are intended to provide a capsule summary of each of the ten document types.

\section{DOCUMENT TYPES}

\section{Functional Description}

- Describes the development group's understanding of the user group's requirements for an operational capability.

- Written in "user language", minimizing technical terminology about ADP hardware.

- Contains an analysis of methods, impacts, cost, requirements, and operating environment.

- Submitted to the user for concurrence, and to user management for approval, prior to preparing detailed system specifications.

- Basic reference document for determining the impact of any change to the scope of the project made prior to user acceptance.

- Contains a development plan identifying milestones and participation by other organizations.

\section{Data Reguirements Document}

- Describes the development group's requirements for data, and the user group's data collection effort to establish and maintain system files.

- Written in user terminology.

- Contains descriptions of input data, procedures and constraints in data handling, expected outputs, and specifications of data elements.

- Submitted for user concurrence; serves as a source of data specifications for the development group.

- Basic reference document for description of data.

\section{System/subsystem Specification}

- Describes the system structure, function, and flow to analysts and programmers in the development group, at a level of detail beyond the functional description.

- Written as a technical document, in enough detail to carry out program design and coding.

- Contains performance requirements and design logic for the system/subsystem.

- Submitted to development management for review and approval.

- Defines the types of interfaces with other systems/subsystems and the operating environment.

- Basic reference for assessment of impact of design changes approved by the user, within the scope of the described system.

\section{Program Specification}

- Describes the program requirements to analysts and programmers in the development stage.

- Written as a technical document, in enough detail beyond the system specifications to describe adequately the component functions, outputs and performance to permit program coding and testing.

- Contains performance requirements, instructions for operations, data structures, and program logic.

- Submitted to technical development management for review and approval. 
- Describes the attributes of data bases, and data elements contained therein, when several groups are involved in maintaining and using the same data base.

- Written in data base terminology, for use by programmers and by data base managers.

- Contains detailed information to permit coding, data base generation, and maintenance.

- When a data base management system is used, this document may supplement the DBMS documentation.

- Alternative formats are described; however, to achieve consistency in presentation, the following practices should accompany the use of this document type:

- Establish the order of contents; for example, as given in the content guidelines.

- Follow each item description with the formatted arrangement of data.

- Descriptions and naming conventions should be consistent with your data base administration policies and conventions.

\section{User's Manual}

- Describes how the user group will use the automated data systems and computer programs prepared by the development group.

o Written in user format, with user terminology.

o Contains instructions and procedures for data entry, equipment operations, interactive queries, and sample outputs. Sections 1 and 2 are directed toward user management. Sections 3 and 4 are directed to the users.

- Submitted to user management and staff for approval, and may be used as basis for training.

- Basic reference document for determination of the impact of changes on procedures, and impact of computer system changes on procedures. Has the equivalent level of detail for users as the Program Specification does for the development group.

\section{Operations Manual}

- Describes how the computer operations personnel will initiate, run, and complete processing of the job.

- Written in operations terminology, and usually follows a step-bystep-scenerio.

- Contains instructions and procedures for routine operations and for recovery (i.e., non-routine operations).

- Contains instructions and procedures for remote terminal operations, if they are required for data entry or remote batch operations.

\section{Program Maintenance Manual}

- Describes the accepted, operational computer programs for the maintenance programmers, who are responsible for making changes to those programs. The design approach, program logic, related data, and operating characteristics are described.

- Contains diagrams and listings of source code for the operational version of programs, and narrative explanations of interfaces, parameters, codes, and messages.

- Describes interface and dependencies with the operating system.

- Provides a history of changes within the scope of the original requirements.

- Refers or contains test information and test data. 
- Describes the test plan, testing procedures, test criteria, and evaluation criteria.

- Written as a non-technical document for users and staff personnel conducting tests; and in appropriate technical terminology for analysts, programmers, and operations personnel.

- Contains test specifications and details concerning the step-bystep testing procedures.

- Testing procedures should cover all interfaces among system/subsystems, programs, and data bases; and describe the relationship among test programs or functions.

- Test methodology; data, and results should be retained for verification of the tests.

\section{Test Analysis Report}

- Describes the results of the test.

- Written for management, describing the test results for management decision regarding the acceptability of the product. Results should be compared to the operational requirement and performance capabilities to assure that all design changes have been incorporated.

- Describes deficiencies and corrective actions necessary for acceptance or, if the deficiency is not corrected, the impact on the system.

- Contains explicit user acceptance in his statement that the system is ready for operation.

- List of improvements which can be made in design or operation of the system as determined during the test period.

\section{CONCLUSION}

With an understanding of the audience and content guidelines, the writer of documentation can now turn to the preparation of project documents using his respective Agency style, forms, and format conventions.

FIPS PUB 38 has, as a Federal guideline, a high degree of flexibility in its application and implementation. Any and all feedback to TGl4 concerning your experiences in using it will provide us with the information needed to make the changes to better suit Federal ADP managers. 
Mark Silverman

Technical Staff Assistant

U. S. Geological Survey

National Center, Mail Stop 801

Reston, Virginia 22092

For the remainder of the symposium there will be three parallel sessions, as follows:

Session A, which is slanted towards executives, user managers, and project managers, will be moderated by Robert V. Head. Mr. Head is the Assistant Director of the Office of Automated Data Systems at the U.S. Department of Agriculture. He has been with the Department since 1971, and has held several key positions as a computer executive. Before entering government service, Mr. Head worked for several years as an information systems consultant. From 1963 to 1965, he served as Vice President in charge of systems planning for Security Pacific National Bank. He was associated with International Business Machines from 1959 to 1963, first as a senior systems engineer and later on the staff of the IBM Systems Research Institute. Earlier, he worked as a manager and programmer for General Electric and UNIVAC. Mr. Head holds the Certificate in Data Processing of the Data Processing Management Association, has twice served as a National Lecturer of the Association for Computing Machinery, and is a past President of the Society for Management Information Systems. He served as a Contributing Editor of Datamation magazine from 1965 to 1971 . He is the author of three books and more than 40 papers in the field of business systems. He received a B.A. in Government from George Washington University, where he was a member of Phi Beta Kappa.

Session B should be of interest to ADP systems, Operations and Programmer Personnel, and will be chaired by Thomas P. Giammo. Mr. Giammo is the Director, Division of Statistical processing, at the Social Security Administration. In this capacity he is responsible for the computer processing of all internal management, administrative, and statistical research activities of the Social Security Administration. Before joining the Social Security Administration, Mr. Giammo was Deputy Director, Data Management Center, at the Department of Health, Education and Welfare. Prior to entering government service, he was Director of the Washington Computer Center of TRW Systems, and he also was associated with Gulton Systems Research Group, Inc. as Vice President. Mr. Giammo received a B.S. in Math from R.P.I. and a M.A. in Math from U.C.L.A.

Session C, which is aimed at those of you who are interested in standards, Training, Policy, and Audit will be chaired by Harris G. Reiche. Mr. Reiche is Director of the Office of ADP and Telecommunications Management, Department of the Interior. He is responsible for policies, planning, and reviews pertaining to the acquisition and management of automatic data processing and telecommunication resources throughout the Department of the Interior. During 1974-75, he served as Chairman of the Government Interagency Committee for Automatic Data Processing. He came to the Department of the Interior in September 1973, with the responsibility for establishing a Department ADP management organization. Previously, Mr. Reiche had served 22 years with the Department of Defense--since 1957 , within the data processing field, where he served primarily in ADP planning and policy roles with the Department of the Air Force. His last assignment prior to joining Interior was as Director of Policy. Technology and Standards, in the office of the secretary of Defense. During this period, he also served on the Information System Technical Advisory Board of the American National Standards Institute. Mr. Reiche received a B.S. in Business Adminiseration from the University of California, Berkeley and an M.S. in Information Systems from George Washington University. 
Robert V. Head

Office of Automated Data Systems

U. S. Department of Agriculture

Washington, D. C. 20250

Let me begin by providing a brief profile of the Department of Agriculture's ADP operations. In terms of size, we fall between the two other members of this panel. We are a lot smaller than DoD, and somewhat larger than HUD; with an ADP budget of about $\$ 65$ million. Approximately two-thirds of our ADP funds are devoted to application development and maintenance, so the subject of documentation standards has obvious importance for a manager who is concerned with where the dollars are going.

In general, our environment can be described as one of centralized data processing and decentralized application development. We operate, in the office of Automated Data Systems, four computer centers, and these centers serve 25 using agencies and staff offices. Thus, we have a somewhat centralized operations set-up and a highly decentralized user organization in which application development work is taking place.

The main vehicles for disseminating ADP policy and standards information within USDA are the Departmental Information Processing standards manual and Title 11 of the Administrative Regulations of the Department. We have sought to introduce FIPS PUS 38 material into both of these documents.

We have adapted the system development life cycle found in FIPS PUB 38 , and published it in our Departmental Information Processing standards manual. We are concentrating on documentation during the initiation phase of a project. The reason for this, thinking in terms of management control over ADP resources, is that this is the point at which both executive managers and project managers should see some documentation--before the project has gained approval or moved into the development phase. ADP resources are scarce, and we have projects competing for these resources. We would like our managers to look at each project proposal critically while it is in the initiation phase, or at least before it has gone beyond the definition stage of the development phase. So we've identified documentation requirements that apply both to all USDA agencies and central staff offices. We have tied documentation into a managerial approval process. We believe that by emphasizing the initiation phase and emphasizing the role of management approval based on FIPS PUB 38 type of documentation, we are orienting our work towards managerial interests.

In the Agricultural Regulations, we require that each agency of the Department with a significant ADP budget set up an Application Review Board. We define significant as a million dollars in budget, or more. Agency ADP budgets within USDA range anywhere from $\$ 5,000$ a year to more than $\$ 15$ milion per year. A dozen or so are spending a significant amount of resources on ADP, and have established Applications Review Boards.

The chairman of each board is at a top management level within the agency. We suggest the level of Deputy Administrator for Management. There also should be membership on the board by people who represent the program areas of the agency--the important mission areas of the agency.

As we structure our boards, we do not have the information systems director of the agency serving on the Board. We view the Board as engendering a sort of adversary relationship between the systems development staff and the top management of an agency. The Board is there to look critically at application proposals, to challenge them, to try to make resource allocation 
decisions based on top management's viewpoint, and not on the viewpoints of the technicians in the organization.

The Application Review Boards are charged with reviewing planned applications during the initiation phase, again tied into the FIPS PUB 38 life cycle. A major application must go before the Board for review while it is in the initiation phase. A major application, for purposes of Board review, is one on which $\$ 50,000$ is expected to be spent during the life of that application.

The Board must review all Automated Decision Making Applications (ADMA's), regardless of size. Similarly, the Board must review any planned application, regardless of size, that processes personal information, as defined by the Privacy Act of 1974.

Among the responsibilities that the boards are charged with are:

1. To review cost-benefit analyses of applications.

2. To assign priorities to applications in accordance with their cost-effectiveness and their importance in meeting the program requirements of that agency.

3. To review the implementation schedules of proposed projects in terms of the agency's mission requirements.

There is a form that is intended to help in the review process. The "Request for Agency Planning Data" form is geared to the philosophy and terminology of FIPS PUB 38. It has, two major parts. The top part covers the application initiation phase, the bottom part the application development phase. This means that in the life cycle of a project, two forms must be completed and submitted for review as the project moves through the initiation phase into the application development phase.

There is a date to be provided, which represents the time at which management approval has been secured for a project. There is another date to be filled in which indicates when a cost benefit analysis has been completed for the project. There are also provisions for estimating schedule dates and summarizing cost estimates for the project.

During the initiation phase, we ask for a rather gross indication of what the dollars estimated to go into the project will be. If the project leaves the initiation phase and proceeds into the development phase, there is some additional cost information that must be provided. Within the development phase, we ask for a breakout of schedule dates and estimated costs for each of the steps within that phase. At this point, those most concerned with the project should be able to do a more precise job of estimating their costs. The important thing to emphasize here is that through our procedures and through our high level documentation, we have adapted the life cycle concept of FIPS PUB 38 and some of its substantive information content to our management approval process.

I don't want to mislead anyone by indicating that the system is fully installed and operating smoothly. It is very new in several respects. There are pieces that are missing. For example, we still don't have satisfactory guidelines for doing cost benefit analyses. We look to NBs for further progress in guidelines that will aid in managerial decision making. 
Eugene B. Smith

Data Systems \& Application Division Agricultural Research Service

National Agricultural Library - Room 003

Beltsville, MD 20705

Variations in data processing activities and documentation practices point out the need for flexibility in the establishment and implementation of documentation standards. This paper will briefly explore the thesis that the real and perceived value of documentation can be increased by integrating certain elements of the standards into the management process.

Documentation Style - One may disagree with specific terminology presented in FIPS PUB 38, but it does represent the traditional approach to documentation. Since the concept is presented as a set of guidelines, an agency has considerable flexibility in implementing standards. Compliance will impose a certain amount of formality, which is desirable. In addition to improved applications systems, a significant benefit from compliance should be improved managent procedures in the areas of control, cost/benefit analysis, and planning.

Last Fall I took my graduate students to visit two major oil-related companies in Houston. During the course of the visit, we questioned each of these large companies about the level of documentation required in the development of new applications.

The first company's documentation practices were relatively formal, and by way of implementation they routinely utilized a standards and procedures manual which was about 400 pages long. It was comforting to note that the traditional textbook approach was actually being followed out in the "real" wor $1 d$.

The second company's approach to documentation standards and procedures was completely informal. They had no published standards, and required very little documentation other than a series of working programs. Their approach was that there would always be more than one person available who was intimately familiar with each system. When questioned about the need for a more structured approach, the director indicated that they were results-oriented and could not afford the luxury of more documentation.

The data processing operations of both companies have been successful for many years. The different approaches represent different management styles, and the success of the informal approach may, in part, be attributed to a certain amount of luck.

This contrast in approaches tends to highlight the question of perceived cost versus benefit. What priority do we place on documentation in terms of a completed system? Can we afford to provide adequate documentation? Can we afford not to?

If we were to conduct a documentation audit of a number of DP operations, I am convinced that we would find a very small percentage actually following adequate documentation practices. Why should this condition exist? Would we purchase a software package, which we had to maintain, that was seriously deficient in documentation? Probably not.

Unfortunately, too often, we do not consider documentation to be an essential element of internally developed systems. We want to get the system working, and don't really have time for documentation. We fail to recognize that good documentation can significantly impact the value and 
usefulness of a system. Documentation is more than just a few comment statements in a program. It should be viewed as an integral part of the system, and a useful management tool.

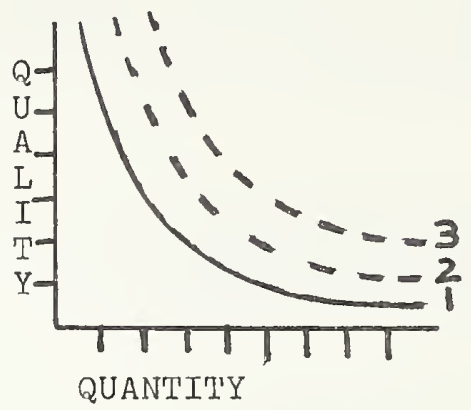

APPLICATION SOFTWARE DEVELOPMENT - PRODUCTION PER UNIT OF RESOURCE

There seems to be a conflict between quality and quantity, as indicated by Curve 1 on the above Figure. In considering the production of a DP organization, it is possible that, by the routine use of good documentation standards, the level of quality for a given quantity of work could be increased, as shown by Curves 2 or 3 .

Documentation Survey - While conducting an internal study to assist in developing documentation standards for the Agricultural Research Service, it was decided that there might be some value in a survey of some 20 sister agencies. The survey was intended to provide a vehicle for determining how documentation was being handled by other agencies, and to allow the collection of documentation material which might be of assistance in our endeavor.

The size of the data processing function varied widely from agency to agency. Agency budgeted expenditures ranged from about $\$ 24,000$ to over $\$ 16,000,000$. Numbers of data processing related employees, ranged from 1 to over 400. Project size ranged from less than one man day to several man years of effort.

While it was possible, during a brief visit, to get some idea of the nature of the standards available, it was not possible to observe how well the standards were being utilized. In terms of existing standards, it is safe to say that they varied from non-existent to very good. Generally, the agencies with few DP professionals needed the most improvement in standards.

Some agencies receive DP support from other agencies, and have virtually no standards of their own. Essentially, they accept the documentation provided. Some agencies "contract out" major projects to commercial firms. In these, the documentation is included as part of the contract, and the results seem to be generally good.

The agencies with large DP professional staffs seemed to be more concerned with the status of documentation standards, and with control over their use. There were a couple of notable exceptions, where relatively small staffs placed a special emphasis on documentation. Two agencies had recently initiated major efforts to develop new documentation standards in compliance with the FIPS and DIPS (our departmental guidelines) publications.

Since FIPS PUB 38 recognizes four levels of documentation, based on usage and cost factors, it is flexible enough to accommodate the range of variation found in the survey. In general, there seemed to be no 
disagreement about the need for documentation, nor was there any quarrel with the guidelines embodied within the FIPS and DIPS publications.

Improving the Perceived Value of Documentation - It should be possible to integrate much of the minimal (or level l) documentation requirements into the internal management control system. Much of the information desired for documentation, is also needed for management. If standard documentation practices are not adequate, one may question the adequacy of management practices.

Consider the types of information generated throughout the software Life Cycle. The information assembled in the initiation phase corresponds to the types of information required to plan, organize, and manage the effort of a DP organization.

It should be possible to design a Service Request Form that would serve both the documentation and management processes. Such a form could include the following types of data:

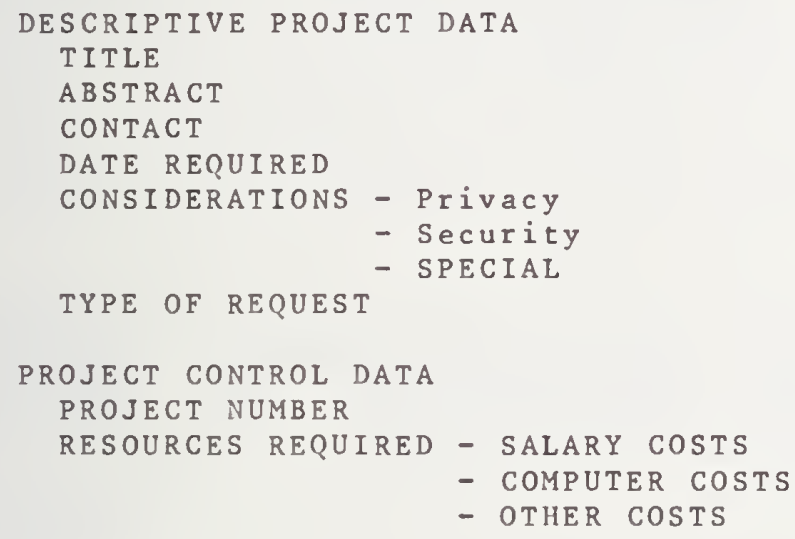

ASS IGNMENT DATA

TARGET DATES

The minimal documentation level would also include other material, depending on the nature of the project. Higher documentation levels would include additional elements, as described by FIPS PUB 38 . An integration of management and documentation procedures provides a necessary element of control.

One might emphasize the point that "The Job is Not Finished Until The Paperwork Is Done." The existence of good standards does not necessarily mean that they are implemented in day to day practice. The enforcement of standards requires a continual effort by management. 


\author{
Dr. Marvin Goer \\ Acting Deputy Director, Office of ADP System Development \\ Department of Housing and Urban Development \\ Washington, D. C. 20410
}

The office of Administration has been restructuring the procedures and organizational responsibilities associated with the development of ADP systems and operation of HUD's ADP capabilities. The basic intent of these actions is to: increase efficiency, provide more responsive service, provide for more orderly and systematic ADP planning and budgeting, and provide for the control and accountability of our total ADP resource utilization.

HUD Handbook 2360.1, "Planning Guidance for ADP Data Systems Development", will probably be superseded by a new set of manuals which will incorporate changes to accomplish these objectives. In order to provide HuD's programmatic managers and $A D P$ users with guidelines, and to assist them in continuing with their ADP development planning, while the Handbook is in the revision and clearance process, ADPSD has prepared a description of the ADP system development cycle showing the traditional system development cycle as it is affected by the revised policies. This guidance should be considered interim, even though these same concepts are serving to structure the Manuals.

The new Manuals, when they are issued, will incorporate a new conceptual approach. The ADP System Development cycle will be covered comprehensively, from Initiation and Requirements Analysis through Budget and Resource Allocation, Specification, Design, Programming, Test and Development Implementation, Acceptance, Operation, and Maintenance.

The purpose of this paper, therefore, is to describe how the ADP system development process is intended to be implemented. Of necessity, the description is of a norma? sequence, recognizing that there may be exception conditions determined by overriding Departmental priorities.

The charts which follow deal with four (4) major classes of ADP application systems. While it is always difficult to define precise bourdaries, we believe the definition of each major classification is sufficiently precise to differentiate among the vast majority of HUD's ADP application systems.

Application Systems Types:

A. User Unique - These applications have the following characteristics:

1. They are not mandated (Handbook).

2. They are generally relatively small.

3. They generally do not require routine and frequent use of internal HUD computing capacity.

4. They may be "one-time" or have a short life-cycle.

5. They generally address a local or limited organizational, administrative or programmatic need.

B. Single User/Single Program - These applications have the following characteristics:

1. They are mandated (Handbook).

2. They are for Department-wide operation or use.

3. They are devoted to a single Program (or set of related Programs) or a single organizational element (or set of related elements within an organization).

4. They are generally operated in HuD equipment.

5. They are routinely and frequently scheduied for operation. 
6. They have a relatively long forecasted life utilization.

7. They are generally maintained and operated by HUD personnel.

C. Single User/Multi-Program or Organization - These applications have the following characteristics:

1. They are mandated (Handbook).

2. They are for Department-wide operation or use.

3. They are generally functionally oriented, wherein the function is delegated to a single organizational element with oversight or support responsibilities across Programs and/or organizational elements.

4. They are generally operated in HuD equipment.

5. They are routinely and frequently scheduled for operation.

6. They have a relatively long forecasted life utilization.

7. They are generally maintained and operated by HUD personnel.

D. Multi-User/Multi Program or Organization - These applications have the following characteristics:

1. They are mandated (Handbook).

2. They are for Department-wide operation or use.

3. They are generally in support of combinations of functions and Programs which cross organizational and Program elements.

4. They are generally operated in HUD equipment.

5. They are routinely and frequently scheduled for operation.

6. They have a relatively long forecasted life utilization.

7. They are generally maintained and operated by HUD personnel.

The "lead" responsibility for performing each task and for developing the system products, which are enumerated, is indicated by the first code in each cell. Tasks and products which require support from, and coordination with, additional organizational elements are indicated by the codes following the lead indicator. ( $U$ = User organization, $S=A D P S D, 0=A D P O, D$ $=O M I-D B M$ )

\section{ADP SYSTEM DEVELOPMENT CYCLE (BY TYPE)}

1. SYSTEM INITIATION AND

REQUIRE MENTS ANALY STS

Initiation

$\begin{array}{ll}\text { A } & \text { B } \\ \text { U } & \text { U } \\ \text { U } & \text { U } \\ \text { U } & \text { U } \\ \text { U } & \text { U } \\ \text { U } & \text { U } \\ \text { U } & \text { U } \\ \text { U } & \text { U }\end{array}$

$\begin{array}{cc}\mathrm{C} & \mathrm{D} \\ \mathrm{U} & \mathrm{U} \\ \mathrm{U} & \mathrm{U} \\ \mathrm{U} & \mathrm{U} \\ \mathrm{U} & \mathrm{U} \\ \mathrm{U} & \mathrm{U} \\ \mathrm{U} / \mathrm{S} / \mathrm{D} & \mathrm{U} / \mathrm{S} / \mathrm{D} \\ \mathrm{S} & \mathrm{S}\end{array}$

This is the traditional first phase in the identification of a system requirement. Frequently it has been referred to as "need identification". Included in this phase is a first estimate of benefits and costs. The product of this phase - "The operational Concept" - becomes an initial input to the planning, budgeting and resource allocation processes. ADPSD and OMI will support Users in performing these tasks as required.

A requirement is then merged with all others and a schedule is developed, priority established, and resources are allocated to develop a system(s) to meet the requirement. Following these actions, the development cycle continues. 
Prepare System Plan

Data Element Definition

Data Sources

Data Base Review

Input Specification

Output Specification

Staffing Specification

Training Specification

Concurrence by Program office

Contractor GTR (if applicable)

$\begin{array}{cccc}U & U / S / O & S / U / O & S / U / O \\ U & U / D & S / U / D & S / U / D \\ U & U / D & S / U / D & S / U / D \\ U / D & U / D & S / D & S / D \\ U & U & S & S \\ U & U & S & S \\ U & U & U & U \\ U & U & S & S \\ U & U & U & U / S \\ U / S & S / U & S & S\end{array}$

In this phase of the development process the requirement is defined more precisely, and a system's operational characteristics are specified. The input data and sources are identified and reviewed by the Data Base Administration staff, the processing tasks are specified, etc. In addition to the Data Base review task, Staffing and Training Specifications are identified as discrete tasks to be accomplished and documented. obtaining the concurrence of the "end-user" in the system plan and the specifications are also identified as specific tasks in this phase.

\section{COMPUTER SYSTEM DESIGN}

General System Design

Input Processing

File Creation \& Maintenance

Output Processing

Computer/Communication Design

Maintenance \& Operational Concept

Contractor GTR (if applicable)

$\begin{array}{cccc}\text { A } & \text { B } & \text { C } & \text { D } \\ \text { U } & S & S & S \\ U & S & S & S \\ U & S & S & S \\ U & S & S & S \\ U & S / 0 & S / 0 & S / 0 \\ U & S / 0 & S / 0 & S / 0 \\ U / S & S & S & S\end{array}$

These tasks comprise the basic computer system design effort - sometimes referred to as the "system architecture". The work is largely of a technical ADP nature and results in Design Documents in which the structure, relationship and logic of the various system components are described. A related document is the Maintenance and Operational Concept in which the hardware and application system relationships are described and the necessary operational conditions, i.e., storage, line capacity, processing sequence, manual processing cycles, etc. are documented. In addition, the logic and discipline for the routine operation and maintenance of the system is described.

4. PROGRAMMING

Input Processor ( $\mathrm{s}$ )

File Maintenance Programs

output Programs

Subsystem Test

Total System Test

Computer System Resource Specs.

Communication System Resource Specs.
A

U

$\mathrm{U}$

U

U

U

U

U

$B$
$S$
$S$
$S$
$S$
$S / 0$
$S / 0$
$S / 0$

B

S

S

S

$\mathrm{s} / 0$

$\mathrm{s} / \mathrm{O}$

$\mathrm{s} / 0$
C

S

S

S

$\mathrm{S}$

S/ 0

$\mathrm{s} / 0$

s/o
D

S

S

S

S

$\mathrm{S} / 0$

$\mathrm{s} / 0$

$\mathrm{s} / 0$
These tasks relate to the actual programming programs. A resultant product is the computer and Specifications, basically a further detailing communications resource requirements. and test of the computer Communication Resource of the equipment and 


$\begin{array}{lccc}\mathrm{A} & \mathrm{B} & \mathrm{C} & \mathrm{D} \\ \mathrm{U} & \mathrm{S} & \mathrm{S} & \mathrm{S} \\ \mathrm{U} & \mathrm{U} & \mathrm{U} & \mathrm{U} \\ \mathrm{U} & \mathrm{S} & \mathrm{S} & \mathrm{S} \\ \mathrm{U} & \mathrm{S} & \mathrm{S} & \mathrm{S} \\ \mathrm{U} & \mathrm{U} / \mathrm{S} & \mathrm{U} / \mathrm{S} & \mathrm{U} / \mathrm{S} \\ \mathrm{U} & \mathrm{U} / \mathrm{S} & \mathrm{U} / \mathrm{S} & \mathrm{U} / \mathrm{S} \\ \mathrm{U} & \mathrm{S} / \mathrm{U} & \mathrm{S} / \mathrm{U} & \mathrm{S} / \mathrm{U} \\ \mathrm{U} & \mathrm{S} / \mathrm{U} & \mathrm{S} / \mathrm{U} & \mathrm{S} / \mathrm{U} \\ \mathrm{U} & \mathrm{S} / \mathrm{U} / \mathrm{O} & \mathrm{S} / \mathrm{U} / 0 & \mathrm{~S} / \mathrm{U} / 0\end{array}$

In this phase of the cycle the system products are subjected to test. In order to accomplish the test (either for Field or co systems) the supporting training and documentation tasks must also be accomplished, and coordinated planning must take place.
6. ACCEPTANCE, TURNOVER, OPERATION
A $\quad$ B $\quad$ C $\quad$ D
Criterion Definition
Test Conduct
Test Evaluation
System Installation
Turnover (Acceptance)
System Operation

$\begin{array}{cccc}A & B & C & D \\ U & S / U & S / U & S / U \\ U & S / U / O & S / U / O & s / 0 / U \\ U & S / U / O & S / U / O & S / 0 / U \\ U & U / S / O & U / S / O & S / O / U \\ U & U & U & U \\ U & 0 & 0 & 0\end{array}$

Before a system is released for operation, the conditions which define acceptability must be determined (along with measures), and tests conducted to demonstrate their achievement.
7. SYSTEM MAINTENANCE
A B $\quad$ C $\quad$ D
Technical Assistance
Modifications
Enhancements
Upgrades

$\begin{array}{lccc}U & 0 & 0 & 0 \\ U & S / U & S / U & S / U \\ U & S / U & S / U & S / U \\ U & S / U & S / U & S / U\end{array}$

The system is now in the operational inventory, and is being utilized in accordance with the operational concept and specification previously defined. All systems require continuous attention, and must be periodically refined to suit changes in operational needs. In most instances, major changes to existing systems, to incorporate new functions or to broaden the scope of coverage, will recycle through the development process starting with the Initiation Phase. 
Greg Loss

Public Health Service
$\&$

Tom Kurihara

Agricultural Stabilization \&

Conservation Service

Question:

\begin{abstract}
Is there an awareness by management of the cost of implementing standards such as FIPS PUB 38? My experience has been that a rule-of-thumb estimate to be added to the cost of a project for documentation of a large system is 20-30\%. This is not excessive, however, the realization of the cost of documentation must be addressed.
\end{abstract}

Smith:

Agree that there is an additional cost.

McGreer:

There doesn't appear to be a history of the cost of documentation. Head:

Is there a danger of over-documentation? In USDA, the Application Inventory Forms were developed to obtain information from the agencies in USDA on major applications. We were concerned with compliance and the implications of too much documentation.

Audience Comment:

Must look at documentation costs in perspective, i.e., there is a danger in looking at the "front-end" costs only, whereas taken as part of the cost of the system over its entire life, the cost of documentation is in its proper perspective.

Smith:

Compare training and education costs to documentation costs. Aren't the training and education costs of an organization justified in terms of the return gained from the investment?

Goer :

At HUD, we have tried to address the problem of cost by establishing criteria for the amount of documentation, as described in my presentation.

Kurihara:

Documentation is the end product of the system development activities. It serves as a record of what decisions were made. TG 14 did not, because of its limited scope, address the system development activities or the management activities. Given a management process with estimation techniques, the cost of documentation can be tied to management and project activities, and, therefore, be placed in its proper perspective.

Head:

In my experience, in recent years, I don't recall that management has asked about the cost of documentation and training.

McGreer:

The costs must be addressed, because we need top management support of the standards development effort. There is the danger that as soon as a successful standards effort is developed, such as in the Department of Navy, there is a tendency to downgrade the Standards Group. Top management should be provided with the potential savings resulting from a successful standards development and maintenance effort.

Question:

Has anything happened to bring to top management attention the need for documentation standards and the cost of not having it?

\title{
McGreer:
}

There is the example of the computer security reporting requirements. Top management attention was obtained when a GAO report was issued. I know that we can't always go up to GAO and down the ladder again to get top management attention on everything. Go to your top management and ask for their support, CRUSADE for recognition to save money in the long run. 
Again, we are in a political environment. There is a tendency to want to hurry and expedite systems development because some senior managers want to make an impact quickly and leave it to the bureaucracy to tidy up later. The bureaucracy, in the long run, must document to maintain the systems developed as quick solutions.

Audience Comment:

I review the systems on paper, i.e, documentation, as a regular part of my job. The basic authority is derived from the Budget and Accounting Act of 1950, wherein GAO has the responsibility for approval of all budgeting and accounting systems. There is a need for more management pressure to develop documentation 8 tandards.

Head:

We appear to be a group of computer professionals talking. Are we talking to each other, or is top management here to benefit from this joint selling effort by NBS and CSC?

Audience Response:

Have to use the "carrot/stick" approach. Prepare good documentation during the implementation stage, and present it to top management for their decision on continuation of the project. Show how good documentation supports the decision making process, and provides a basis for potential cost savings or avoidance.

Head:

$\overline{U S D A}$ is committed to the life cycle concept with what we call "creeping commitment" via project documentation. Documentation is the mechanism by which projects are reviewed at each stage and phase of application development. It is the means of oringing management back into the decision cycle as you go on.

Goer:

Good documentation can be your protection against GAO reports, On the positive side, programing is still an "art-form." As a writer, a programmer is forced to write with increased precision and definition when describing the computer program. Managers get better controls and avoid surprises as better documentation is provided. Real benefit to management at all levels is control.

Question:

What is the cost?

Goer:

The price of documentation in the process of delivering a completed product is really a "sunk cost" in the bureaucracy. What is most important to me in the control I have over that procass when good documentation is available for each decision point in the life cycle.

Head:

We should move on to avoid the preoccupation with cost. In any selfregulating mechanism, as dollar costs increases, a method of getting management involvement evolves. Richard Nolan's Harvard Business Review Article "Managing the Four Stages of EDP - Growth and Preparing for the Fifth Stage" describes the stages of EDP development and the different degrees of management involvement.

Question:

Has the value of documentation been addressed in respect to computer program maintenance? The savings resulting from improved maintenance productivity can decrease the number of maintenance programmers, and add to the development group.

Goer:

Usually what happens, because of the political climate we are exposed to, is that if an estimate is made to management of eight months with documentation, or six months without, they will say go with the six months'. 
Head:

In the Federal Government, in my experience, there is a general 1 ack of continuity between the requirements statement and maintenance of the program. The primary concern is to get it up and running, and avoid the issue of maintenance. On the other hand, there is a greater concern for continuity of development and maintenance for commercially developed software.

McGreer:

Take the life cycle approach. The cost of documentation is repaid over time. The SAGE system maintenance problem was created as a result of having a cascading series of different equipment driving the automatic projection at the command center. The programs had to contain performance profiles for aircraft and weapons systems. Changes were needed as aircraft and weapons changed. The cost savings were realized in making the changes more easily. Audience Comment:

I think I have a feel for the maintenance cost. In our organization, I run only a maintenance shop, we do not accept any software for maintenance from the development shop without usable documentation. We use our standards as a basis for judgment. Of course, there are roughly four orders of magnitude in documentation and maintenance. It goes from the 1401/650 programs still being run, which, taken overall, takes 2 man-years to maintain; to the well documented system, which can be changed in a day or two per month.

Question for Mr. Head and Dr. Goer:

How does your agency currently control and audit your Department's compliance with your standards program? What plans do you have in the future for this control?

Head :

In USDA, we work closely with the internal office of Audit (oA) staff. OA is staffing up to be able to address auditing of the system development process. We have had to be careful to avoid over-documentation, and therefore tried to establish threshold values for submitting application documentation for approval; e.g., not for systems with an annul cost of less than $\$ 25,000$.

Goer:

Our problem is sma1ler and easier to manage. The Assistant Secretary for Administration is charged with the responsibility for controlling systems used strictly within his area of responsibility. We do that through a staff function which combines standards, quality assurance, and quality control. He cannot control systems which are being developed in other areas under the other Assistant Secretaries.

Sinith:

One agency I surveyed ran uncertified programs as stand-alone jobs until they could be certified. They would then be eligible for cataloging to the production library.

Audience Comment:

We at GAO visit various agencies to review systems and to assess the readiness of documentation prepared in support of computer systems.

Question for Dr. Goer:

You mentioned that you do not document those systems which prepare Congressional reports. In those instances where Congress might find the system useful, and in fact, decide to fund on a priority basis, how do you then go back and document?

Goer:

One time requests for retrieval are recorded for effort and accomplishment, but are not documented. Because they are one time data extractions through a DBM language, a new DB was not created. 
Are states expected to comply with these standards (FIPS PUB 38 ) on systems developed with, or supported by, Federal funds?

\section{McGreer:}

Over time, there will eventually be some type of compliance, if the Privacy Act of 1974 can be used as an example. The efficiency considerations will eventually push in that direction.

Head:

I believe that OMB Circular A-90 specifically addresses that question. It prohibits any strings to be attached to grants, or on other requirements levied by the Federal programs.

Kurihara:

There is a non-profit firm, Public Technology, Inc., which is assisting local, municipal, and state governments on the exchange of technology under the sponsorship of HUD. They have developed some documentation standards for exchange of information about computer-based systems. Generally, the concepts are transferred, and the implementation of a transferred system is accomplished with sufficient changes to suit the receiving organization. But there is a tangible benefit of having standard documentation guidelines as a supplement to personal contact. The participating local, municipal, and state government representatives all agreed that the standards developed in their group will be beneficial. A member of FIPS TG 14 was an observer at the working group sessions.

\section{Question:}

How is TG 14 organized to assist in using FIPS PUB 38 ? What is the schedule For issuing the feasibility study, cost benefit analysis guidelines?

Kurihara:

Thank you for providing us with the opportunity to announce the activation of a subgroup chaired by Mr. Roy Young, DHEW, to provide assistance to users of FIPS PUB 38. We are ready to provide the required assistance.

Audience Comment:

The review process in the maintenance of the DOD standard has worked. It can work the same way at the Federal level. We are now working on the second revision to 4120-17M. The first revision is in the publication process. As people get more familiar with the standard, they have more input to it and we are continously getting new ideas. (For further information, contact Don Wagus, US Army Computer Systems Command, 664-4411).

Head :

In closing, I will use the 5 questions listed on the symposium program to try to review what we discussed.

- Can the guidelines help?

- A qualified YES. There is a need to seek management review at the ADP policy level.

- How can the manager evaluate technical documentation?

Levels of documentation standards should be identified with the lower levels, so that top management can handle only the appropriate details.

- Is documentation worth the cost?

Much concern and preoccupation with cost. Benefits can be obtained by making presentations to top management, showing that the series of documents produced during the development period are a means of clarifying requirements, improving the effectiveness of the development effort, and easing the maintenance of systems.

- How can software quality be assured through documentation?

A better understanding of software results from improved documentation.

- Do existing systems need to be documented?

Existing systems need to be documented as changes are made. For the technical people, you must devise methods of getting management attention to support good and complete documentation. 


\author{
Thomas Giammo \\ Social Security Administration \\ Health, Education, and Welfare \\ Baltimore, Maryland 21235
}

Welcome to Session B - "ADP Systems; Operations, and Programmer Personnel" As one can tell from the title, this session is designed to explore those aspects to FIPS PUB 38 which affect the working level personnel of a data processing operation.

My name is Tom Giammo, and it's my function to serve as moderator of this session. Before introducing the members of the panel, I would like to go over some of the ground rules I intend to follow in this session.

First of all, I've asked that the discussion and question/answer phase of the session not be taped. The introductory addresses of the panel members, however, will be taped, to assist in the preparation of proceedings. Although it would have been helpful, in this regard, to tape the discussions (since a synopsis of these will also appear in the proceedings), I felt that it might tend to inhibit open discussion. The primary purpose of this session is to initiate a frank and open dialogue between TG-14 and the FIPS PUB 38 "user community". To accomplish this purpose, it is necessary that negative opinions, unflattering examples of current practices, etc. - all be freely expressed, without fear that such remarks might be traced to any individual.

Second1y, I've asked the panel members to lead off the session with presentations. I would like to ask that no questions be initiated during these presentations, since they are scheduled to last the entire "pre-1unch" period. I hope, however, that you'll be able to save all your questions until our "after-lunch" period, when I'll turn the floor over to the audience.

Let me begin by giving you some information about myself and the panel. I'm currently with the Social Security Administration, where I'm responsible for the data processing center, which services the statistical, administrative, and management functions of SSA. We've begun to feel the impact of FIPS PUB 38 in my organization, and have already begun to extend parts of the guidelines to cover our specific procedures. My association with FIPS PUB 38 and TG-14 goes back much further than that, however. In the mid-1960's, I had the dubious honor of being one of the "guinea pigs" used by NAVCoSSACT to try out the initial draft of their documentation standards. At that time, I headed the Washington office of a software consulting firm which had a contract with NAVCOSSACT. Although we had severe problems with this standard, I was intrigued with the possible advantages (not only to NAVCoSSACT, but also to the vendor) of such standards. Consequently, we put a lot of effort into our comments on the standards, and worked closely with the NAVOCCACT personnel on testing revisions. As time went on, and the standards improved, my initial optimistic appraisal of the potential benefits was confirmed, and I became an enthusiastic supporter of the standards. As mosi of you know, these NAVCOSSACT standards became the basis of NAVY-wide standards, which in turn became the basis of DOD-wide standards, which in turn were the starting point of TG $14^{\prime} s$ efforts with FIPS PUB 38 .

This brings me to our first panel member, Bob Hegland. Mr. Hegland represents the single thread of continuity through the entire evolution of FIPS PUB 38, from the initial NAVCOSSACT standards. I met Bob back in the mid-60's, and since then I've stayed abreast of the documentation standards field through him. He was an active member of each of the intermediate 
standards groups (NAVCOSSACT, NAVY, DoD), and is a key member of TG-14. is still with NAVCOSSACT, in the documentation standards area.

Mr. Shirley Alger is a co-worker of mine at the social security Administration. I've asked him to be a member of the panel because he represents essentially the entire sum and total of the social security Administration's experience with the implementation of FIPS PUB 38 , at this stage. He has been given the task of organizing the programming documentation standards activities of the office of Management and Administration. He chose, I think properly, to attack this responsibility with the aid of FIPS PUB 38. His experiences, so far, are valuable, in that he has run into some of the difficulties all of us will encounter. Some of the ways in which he is going about trying to solve these problems will be instructive. Most important, there is at least a touch of the real world in his experiences. They may prepare you for what will really happen when you try to put these guidelines into the form of a standard to be used by your organization.

Mr. Herb Bright is well known to anyone who has been involved with ADP standardization. Herb has made many significant contributions to computing in general, and I felt his broad range of experience would be useful ro draw upon. I especially asked Herb to join the panel because he comes from outside the federal government. He's currently President of Computation Planning, Incorporated, which is a private, software-criented, consulting Firm. I think Herb's experiences in using various government documentation standards will be of interest to anyone documenting software using the FIPS PUB 38 Guidelines.

It is my view that the purpose of this session is to create a general awareness of the problems associated with the implementation of the guidelines, in the form of standards for individual agencies, departments, etc. What I hope we can explore, in some depth, is the considerations which management ought to be aware of before committing their organizations to the guidelines. It is my personal feeling that it would be most detrimental for management just to take the naive attitude that the existing guidelines can be "adopted" as standards by simply issuing a memo to that effect. That kind of approach will not only have the immediate effect of failure, but is bound to have a longer term effect of convincing people that the concept of documentation standards itself is faulty. If, in this session, we can meaningfully explore some of the more important of the management considerations which should be part of the implementation of the FIPS PUB 38 Guidelines, I would feel that we have had a successful session, well worth the time and effort of everyone involved.

In trying to shape this session toward that goal, we each have distinct roles. I have the easiest role of all. As session chairman, it's my responsibility merely to state the problem and to "oversee" the resultant discussion. (I don't intend to be too rigorous about overseeing the discussion - if the group's excitement and enthusiasm is so great that the session gets out of hand, I think we would be achieving our original purpose.) The panel members are here to start the discussions. Their presentations are intended to explore, only partially, limited aspects of the problem. In the open discussion period, I hope to have them serve as a target for your questions and as a foil for your opinions. You, the audience, have the most important role. I expect you to lead the discussion, challenge the views of the panel, explore unaddressed aspects, recount relevant experiences, suggest alternatives, etc. I want to emphasize that I will positively encourage alternate viewpoints, criticisms of the guidelines, etc. There is a natural tendency in conferences such as this to have only the enthusiastic "boosters" do all the talking. The panel and I are obviously biased in this direction - we wouldn't have been invited here unless we weren't already associated with documentation standards. I'm going to insure that we don't monopolize this discussion. 
To start off the presentations, I've prepared a few slides wich give my view of the important aspects of problems in the implementation of documentation standards from the FIPS PUB 38 Guidelines. In the hope of creating a common basis of discussion I have previously distributed these to the panel members and asked them to at least consider them in drafting their presentations. I also intend to return to these topics in my final summarization at the conclusion of the session.

(Transcription of slides in lieu of text of remainder of presentation.) 
IDENTIFY POTENTIAL PROBLEM AREAS

- EXPLORE INTERACTION WITH DOCUMENTATION GUIDELINES AT WORKING LEVEL:

- ARE THE GUIDELINES GENERAL ENOUgh IN SCOPE?

- ARE THE GUIDELINES TOO ABSTRACT TO APPLY IN PARTICULAR CASES?

- ARE the gUidelines COMPREhENSIVE ENOUgh tO PRODUCE SATISfactory DOCUMENTS?

- DO the guidelines provide a NATURAl INCENTIVE For ACCEPtance by ASSISTING THE "WORKERS" IN THEIR RESPONSIBILITIES?

- DISCUSS APPROACHES TO PARTICULAR PROBLEMS:

- ADAPTATION OF GUIDELINES TO PARTICULAR WORKING ENVIRONMENTS

- SYSTEMS, OPERATIONS, PROGRAMMER FAMILIARIZATION AND TRAINING

- ELIMINATION OF "PASSIVE RESISTANCE"

$$
\text { SLIDES II, III, IV, \& V }
$$

DISCUSSION TOPIC "SEEDS"

- ARE THE GUIDELINES GENERAL ENOUGH IN SCOPE?

- Do they CAPture the essential elements of Systems encountered IN THE "REAL WORLD"?

- ARE THEY TOO BATCH-PROCESSING ORIENTED?

- ARE THE GUIDELINES TOO ABSTRACT TO APPLY IN PARTICULAR CASES?

- CAN WORKING LEVEL PERSONNEL RELATE THEIR INFORMATION INTERFACE REQUIREMENTS TO THE CONTENT SPECIFIED IN THE GUIDELINES?

- ShOUld THEY BE REINTERPRETED, EXPANDED, MODIfied TO MATCh lOcal ENVIRONMENT?

- ARE THE GUIDELINES COMPREHENSIVE ENOUgh?

- ARE all the ELEMENTS OF A SYSTEM WHICH REQUiRe dOCUMENTATION ADEQUATELY ADDRESSED?

- WILl DOCUMENTATION PREPARED IN ACCORDANCE WITH THE GUIDELINES BE SATISFACTORY?

- Do the guidelines provide a natural incentive For, acceptance by ASSISTING THE "WORKERS" IN THEIR RESPONSIBILITIES?

- WHAT DO THE GUIDELINES DO FOR THE PROGRAMMERS, OPERATIONS, SYSTEMS PERSONNEL?

- WHAT FAMILIARIZATION, TRAINING, ETC. IS NECESSARY? 
Robert R. Hegland *

Naval Command Systems Support Activity

$($ Code 70.3$)$

\section{INTRODUCTION}

The items that follow contain a discussion of some of the problem areas that have been raised in the past regarding computer program documentation standards and guidelines. Most of these problem areas can be resolved; some cannot. There are few standards or guidelines that are perfect and about which no questions can be raised. The guidelines contained in FIPS PUB' 38 are the product of not only the FIPS committee, but also of many other committees and individuals who have worked with its predecessors. Each of these committees raised questions and resolved them by changing and enhancing the documentation system. A characteristic of a guideline such as FIPS PUB 38 is that it must be reviewed, updated, and changed as our experience grows.

\section{AUTOMATED RUN INSTRUCTIONS}

Some organizations now generate what they call Automated Run Instructions from the run streams of their programs. They have asked if this removes the need to produce an operations Manual. It is, of course, up to the central office or the implementing organization to review this question in detail and determine whether all of the items of information in the operations Manual are covered by the Automated Run Instructions. My reaction is that there are certainly some parts of the operations Manual that can be replaced by such run instructions. There are other parts, however, that are probably not a part of the run instructions, such as the Program Inventory, some of the information about the output Reports, and information about Non-Routine Operations and Remote Operations.

II I. REAL-TIME, ON-LINE

Systems that perform real-time, on-line operations, and that may have a fully dedicated computer to run them, have always been a problem to document in terms that users can understand, since the documentation must be sequential, and the programs can run in different sequences. Whenever possible, with these types of systems, it seems to be a good idea to build as much tutorial information into them as possible. There doesn't seem to be any all-encompassing solution to this problem for the User's Manual. The Program Maintenance Manual can, of course, still be written as shown in the Guideline, since it can be sequenced by program or module. The operations Manual would need to be quite different from that in the Guideline, since there is very little operator intervention or action required in most of these systems. Instead, the terminal operator, who is really a "user", has significant control over what is largely operator functions in nonterminaloriented systems.

\section{IV . STRUCTURED PROGRAMMING}

The question has been raised in the past about whether this documentation system can be used to support structured programming projects. The general feeling on several committees is that there is no essential difference in documenting structured programs and programs written using other techniques. As a matter of fact, a large contractor looked at that problem with the DoD version of the documentation standard, and had only a very few changes to recommend. Most of these changes did not have a significant impact on the DoD standard.

\section{COBOL}

The statement has often been made that coBol is "self-documenting" and the question has been raised as to how this relates to the documentation Guideline. COBOL is certainly written in English-like statements, and that 
is a great aid for a programmer who is trying to determine what the program is doing. With COBOL, there is still, however, a need to prepare a Program Maintenance Manual (particularly for a large system), since a new programmer still needs a narrative overview to use in becoming familiar with the basic structure of the program system. There is no need, in the Program Maintenance Manual of a COBOL program, to include a detailed narrative of the logical flow of the program. CoBol is not, however, "self-documenting" for a user to read or for a computer operator. Consequently, there is still a need for written documents for these functions. Since coBoL is, to some extent, self-documenting, then if the program has been well commented, less detail needs to be included in a written document on the program than would be needed if the program were written in a less familiar language or in machine language.

\section{PROGRAM MAINTENANCE MANUAL}

There has been a proposal that the Program Maintenance Manual isn't really needed, and that it should be replaced by the Program specification, which was written during development, and kept up to date as the programming progressed. The Program Maintenance Manual, of course, serves several purposes, such as to support the transfer of the system to another organization, or in training new programmers in maintaining the system. The approach of using the Program Specification as the Program Maintenance Manual can be made to work, but there are some very real problems in doing so. First, it means that a Program Specification would have to be written during the development of each and every system. Using this approach also means the Program Specification would have to be updated constantly as the system was developed. This updating seems to be difficult to do in the real world. This, again, is something that a central office needs to look at very carefully in implementing the Guideline.

\section{TERMINOLOGY}

One of the continuing problems with this Guideline, and with all guidelines standards, is that the terminology may mean different things to different organizations. For example, a "system" means, to some people, the hardware and software; to others, the term means the application system being programmed. This Guideline has been written, as much as possible, using basic ADP terms that have generally accepted meanings across all organization lines. If input is received from a satellite, for example, it is still input; the fact that it comes from a satellite won't be mentioned in the Guideline. A related problem in all guidelines and standards is that they must be written in English. Even though we have a standard Dictionary for Information Processing, we still have to use English to communicate our thoughts and ideas, and English is an imprecise language that allows what one person writes to be interpreted differently by another person. In using the Guideline, authors should remember that it was written to cover as many different organizations and situations as possible. It is necessarily subject to interpretation. Authors should try to fit what is included in the Guideline into their own environment.

VIII. CONCLUSION

Problems perceived in using the Guideline depend on how thoroughly it has been reviewed and understood, both by the authors and the implementing central office. Some problems are harder to resolve than others, but the central office needs to anticipate as many problems and questions as possible, so that implementation guidelines can be promulgated at the same time as the Guideline. Many of the problems that arise are those that have already been addressed and discussed in section 2 of FIPS PUB 38.

* The comments contained herein are the author's, and do not necessarily represent policy of the Department of the Navy or of any naval activity. 
Robert A. Mattes

$\&$

Social Security Administration
Kenneth Rodey

National Security Agency

Question:

There appears to be a lack of guidelines to instruct individuals on how to handle changes in the Maintenance Manual. Was this deliberate?

Pane 1 Member:

Yes, the guidelines were omitted intentionally, to allow each organization the opportunity to develop its own administrative procedures for handling changes to the Maintenance Manual. It was assumed that each organization handles the posting of changes differently (e.g., change pages, complete rewrite, etc.).

Panel Member:

Because of the large investment in Application Programming, there is a definite need for a reliable access audit-trail, to protect programs from being modified without maintaining a documented record of those modifications. However, there is currently very little attention being paid to this matter. In general, subtle changes to computer programs are not backed up by Audit Trail Documentation. Because of this, existing Program Documentation seldom reflects the true nature of the program that it describes.

Panel Member:

The Social Security Administration has a Customer Billing system that maintains a $\log$ of what systems are being used and by whom.

Panel Conclusion:

The Maintenance Manual lends itself possibly to assist in assuring that changes are properly documented. It also assists in exploring the ramifications of a pending modification. However, without rigid procedures on posting all changes to it, the Maintenance Manual would soon become obsolete.

Question:

Is there a provision to include, in the Data Base Documentation, a list of what programs are allowed to access the data base, and what fields they access?

Pane 1 Member:

There is currently provision for the identification of all software (computer programs) which access the Data Base (see section 2.2 of the Data Base Specification). As can be seen, this provision does not identify which programs access which fields. This identification could be handled by section 3.C of the Data Base Specification, when describing the Logical Characteristics of Fields. However, the maintenance of such a cross reference list should be handled through an automated system rather than a manual system. FIPS Task Group 17 is now developing guidelines for Data Resource Directories, which will address the issue of relationships between data and the processes which work upon it.

Question:

Of the 10 documents, how many should be used to retrofit existing programs? Is it practical to retrofit documentation of on-going programs?

Pane1 Member:

There is no general rule for determining which documents should be used, or the level of detail to be recorded for each. This is determined by the needs of the individual organization. It is advisable that an organization consider each existing program, independent of all others, when determining the amount of documentation to capture. Because of basic differences among programs (e.g., one-time-shot, large size, frequently used, no longer in 
operation, volatile coding changes, etc.), some programs will require more documentation than others.

Panel Member:

High level management at SSA decided to rewrite its payroll system, rather than produce the necessary documentation for an existing system.

Pane 1 Member:

Every organization will most likely encounter considerable resistance from analysts and programmers concerning the retrofit of documentation for existing programs.

Panel Member:

Typically, management does not know what they want. Good documentation is the physical evidence of what they require.

Panel Member:

Third generation equipment eliminates the need for some of the manually produced documentation previously prepared (e.g., Operations and User's Manua $1 \mathrm{~s}$ ).

Panel Member:

The burden of documentation is a problem for internal ADP management, whereas user management is unaware that a problem concerning documentation exists.

Pane 1 Member:

User management is often insensitive to the need for documentation, and, typically, does not clearly spell out the application problem, or what their ADP requirements actually are.

\section{Question:}

How do you convince the interactive on-line user to read and follow the User's Manual?

Panel Member:

Typically, the interactive on-line user will not read documentation that exceeds one page in length. Therefore, this necessitates having the user documentation on-line and readily available to the user in a self-teaching mode $(e . g .$, HELP modules).

Question:

Isn't FIPS PUB 38, especially the User's Manual, directed toward second generation computer systems?

Panel Member:

Many parts of FIPS PUB 38 are oriented to, or thought of as being second generation. In fact, FIPS PUB 38 has its historical origin in the mid$1960^{\prime} \mathrm{s}$, when second generation equipment was in prominence.

Panel Member:

It is very difficult to prepare a standard or guideline that would be applicable to a 11 on-1ine interactive systems having various levels of sophistication. Special purpose manuals that support the particular on-1ine system should be prepared in hardcopy or softcopy form to supplement the User's Manual. For on-line systems, the User's Manual could satisfy the documentation needs of top level management of the user organization.

Question:

Have you experienced any difficulties with the Data Requirements Document as it applies to on-1ine systems?

Pane 1 Member:

No, because the Data Requirements Document is developed around requirements, not programs or hardware.

Question:

Who is the author of these documentation manuals, the programmer or the ana 1 yst? 


\section{Pene 1 Member:}

Depending upon the environment of the organization, either programmer or analyst could be the author.

Audience Comment:

Some companies have quality assurance groups that employ writer/editors to confer with the programmer/analyst and actually prepare the documentation for the program/ system. The assumption is made that if programmers cannot explain the system to an editor well enough, then the editor cannot document it. In addition:

1. The editor is a better writer.

2. Analysts can devote their time to Systems Analysis and Design.

3. Programmers can devote their time to programming.

4. The entire operation is more cost-effective.

5. Having to explain processes to a third party leads to better design through structured thinking.

Question:

How would software contractors react to the inclusion of a standard documentation like FIPS PUB 38 as part of the deliverables under a software contract.

Panel Member:

FIPS PUB 38 would be acceptable for second generation type equipment, but the contract would have to be explicit about which documents, and which items within them, should be included, and how they relate to the system being developed.

Question:

Would FIPS PUB 38 be applicable to small dedicated mini-computer systems?

Pane 1 Member:

Absolutely, since dedicated, departmental, mini-computer-based systems typically resemble late first generation or early second generation computer systems, for which FIPS PUB 38 is ideally suited.

Question:

38 attempts to define what is minimum documentation. Has the Social Security Administration established what they feel is too much documentation for different circumstances?

Pane 1 Member:

SSA has not established any general guidelines, to be followed by those who develop systems, on what is too much and what is too little. However, we are attempting to determine documentation requirements by requesting our four applications divisions to gather all available documentation together, and to compare it to FIPS PUB 38. Then we ask them to comment on the ten document types as being C-Complete, I-Incomplete, or NA-Not Applicable.

Question:

Does the Program Maintenance Manual present an overall, detailed picture of the System for the analyst, who has to determine what ramifications a given change will have on the entire system?

Pane 1 Member.

No, because the Program Maintenance Manual is intended to present a detailed description of a given program; not the entire system. Perhaps, if the functional requirements document and the system/ subsystem specification were kept up-to-date, they could be used to determine the impacts of changes.

Panel Member:

A cross-reference grid showing the relationships between programs and data elements/items could be prepared to supplement the Program Maintenance. 
Question:

Does anyone prepare and maintain their documentation using interactive text editing systems?

Panel Member:

Yes, SSA currently does some, and will be receiving additional equipment to expand this effort.

Question:

There appears to be a lack of understanding, or a misinterpretation, of the contents of FIPS PUB 38. What do "paragraphs" mean, and to what extent should information be described?

Pane 1 Member:

The first two documents that are created in an organization are hard to produce, and require a great learning process. Each organization will have to develop its own interpretation of the content of each document, and the degree of detail to be described for each.

Question:

The contents of similar sections of many of the documents seem to capture reduncant information (e.g., Operating Environment is specified in both the Functional Requirements Document and the System/subsystem Specification). Was this deliberate?

Panel Member:

Yes, information has been included in each document to provide a "standalone" understanding of the document, with a minimum need for crossreferencing to parts of other documents that may have been produced. However, it would be perfectly valid to set up the documentation requirements in your organization so that information is captured only once in a specific document, or once in a specific section of the overall documentation which your organization records for a given Automated Data System.

Panel Member:

Each organization would have to develop guidelines and examples to follow in the preparation of documentation. FIPS PUB 38 was not intended to be a stand-alone document.

\section{SUMMARY}

1. Are the guidelines general enough in scope? No, to a large extent they are obsolete, since the batch orientation is much too strong and real time, on-line systems are not adequately addressed.

2. In terms of the abstraction of the documentation standard, there is a good deal of ambiguity, and a need for interpretation at the lower levels. FIPS PUB 38 should not be issued without internal guidelines, or else its implementation would be left up to each individual.

3. Are guidelines comprehensive enough? It provides for adequate documentation in those situations for which it was intended, but there is some question about its maintainability.

4. What kind of familiarization training and division of responsibility is best for doing documentation? It appears that using a documentation specialist or tech writer, who is not a programmer or systems analyst, may be the best way to go for quality documentation.

5. The areas of System Level Maintenance Manual needs to be addressed, along with the tools for self-documenting on-line query systems. 
INTRODUCTION: "STANDARDS, TRAINING, POLICY, AND AUDIT PERSONNEL"

Harris G. Reiche

Director, Office of $A D P$ and Telecommunications Management Department of the Interior

Welcome to session C. Now that there is a FIPS PUB 38, what do you do with it? We will be addressing that question from the standpoint of agency staff function. More specifically, for you who are the agency standards managers, or responsible for agency ADP policy, do you turn the guideline into a standard? Do you use it only as a guideline? Do you leave that decision to your bureau or other subordinate organizations? Or even to operational management for your decentralized programming functions? How do you handle training throughout your agency? Whatever your decision is with respect to the foregoing questions, how do you maintain follow-up to assure good documentation?

How should the auditing staff use FIPS PUB 38? How important is use of the guidelines to the success of application programs in meeting their objectives?. How can the auditor improve his performance by using the guideline? Of course there is no single answer to any of these questions. It is unlikely that we could even get agreement among the panel members. It isn't the intention of this panel to develop a canned approach to implementing FIPS PUB 38, but to stimulate a discussion of the issues--to exchange the approaches being taken by various agencies.

The format of the session will include presentations from three panel members, followed by a discussion among the panel members and the audience.

The first panel member, Mike Gall, from the Civil Service Commission, will address some of these issues from the perspective of a relatively small government agency--where, to a great extent, the ADP line and staff organization is the same.

The second panel member is Joe strnad, from the Department of Health, Education, and Welfare. He will discuss the issues from the perspective of a large agency, with large, and often times autonomous subordinate organizations.

The third panel member, Phil Morrison, is from the Department of Housing and Urban Development. He will review FIPS PUB 38 from the auditor's perspective.

The fourth panel member, Roy Young, from Health, Education, and Welfare, was a member of Task Group 14, which developed FIPS PUB 38. He will participate in the discussions following the three presentations. 


\author{
Joseph J. Strnad \\ Department of Health, Education and Welfare \\ office of Management Technology \\ 200 Independence Avenue, S.W. \\ Washington, D. C. 20201
}

Before addressing the questions specified for discussion by this panel, I will first cover the uses being made of FIPS PUB 38 at the present time in this Department; and then discuss how we propose to integrate the documentation concepts contained in the publication into our ADP operations. Hopefully, this will explain our concept of how staff persons, such as assembled here today, can directly influence the documentation process in their departments, in a manner consistent with overall management objectives.

As most of you know, HEW consists of several components, with distinctive missions and varied historical backgrounds. We have organizations that have been around for a long time, such as the social security Administration (SSA), the Public Health Service (PHS), and the Office of Education. (OE); and relatively new organizations like the office of Civil Rights (ocR) and the Office of Human Development (OHD). Needless to say, the older organizations have established documentation practices set forth in systems manuals and standards. Depending upon the quality of such manuals, these agencies are finding FIPS PUB 38 useful in different ways. For example, the Bureau of Data Processing of SSA is revising their operations manual, using FIPS PUB 38 as a guide. The PHS is developing a standards manual, based on FIPS PUB 38, for use by their various component agencies. OE, on the other hand, published their ADP systems manual in september, 1975, which had a chapter on documentation which is very similar to FIPS PUB 38 , since it was partly based on the ANSI publication "Technical Documentation of Computer Projects". Our newer organizations, like OHD, have no documentation manuals, and have found FIPS PUB 38 useful in specifying requirements to contractors for new systems development efforts.

When FIPS PUB 38 was issued in February, 1976, we at the department level recognized that it would have value in varying ways among our components, and experience to date has confirmed that belief. We gave the publication broad distribution in the department - around 800 copies, but recognized that it would take a long time to realize any appreciable impact. A principal reason for not mandating its use was the simple fact that revision of documentation manuals and guides requires resources which may not be available in the agencies' budgets. Also, agencies have their own priorities, and may have requirements that rank above a major overhaul of documentation practices, particularly if they already have a manual or established practices which they consider reasonably satisfactory. In short, we in HEW distributed FIPS PUB 38 as a guideline, to be used as deemed appropriate by its recipients.

However, we did not let the matter rest there. We at the department level recognized the need to assure that all components in the department should strive toward a level of documentation to achieve the goa 1 of FIPS PUB 38 namely "to provide information to suppport the effective management of ADP resources and to facilitate the interchange of information".

Last spring, we launched an overall ADP systems management study project designed to lead to departmental policy regarding life cycle system management, from the planning and budgeting phase through the operations phase. Areas under study are: systems categories, approval levels, monitoring, operational reviews, as well as system documentation within the 
software life cycle. While our initial concepts on documentafion do not exactly coincide with FIPS PUB 38, we have found it a useful guide in our deliberations. In a few weeks, we will be convening a departmental task force to review the various comments we have received from our components, and to finalize our life cycle systems management concepts and policies. It is our objective to establish, within those policies, the requirements for documentation related to departmental ADP management, Again, this is a long-term proposition, but we feel it holds promise of bringing all components into some degree of harmony regarding system documentation. It is very doubtful, in an organization as large as HEW, that we will ever achieve uniform documentation throughout $-\infty$ but we should strive for basic similarity, with minimum standard requirements, to facilitate exchange and use of data and systems. FIPS PUB 38 provides a common benchmark 'for this to occur throughout the federal establishment.

In the near term, I think the philosophy underlying the standard can be promulgated in two or three different ways:

First, I think the FIPS PUB 38 should be required reading by all professionals in the ADP business. Every professional should be familiar with the family of documents in the publication and the suggested content and structuring of the documentation.

Second, FIPS PUB 38 should be required reading at the level within organizations where the responsibility rests for maintaining in-house ADP procedures, including documentation. It should be maintained as a ready reference. If the organization's systems manual is under revision, and the use of FIPS PUB 38 guidance is a feasible alternative, it should be followed. By this means, we can gradually evolve toward a uniform standard for documentation.

Lastly, managers of programs responsible for approving new system development efforts should have a general awareness of the documentation appropriate for various phases in the software life cycle. This will tend to make them more prone to support the resource requirement, and also, it will give them some idea where answers can be found to their system questions. We in HEW feel strongly that program managers being supported by ADP systems, if they are to get their money's worth from the resources they are investing in systems, must develop an awareness of ADP systems and what makes them tick. FIPS PUB 38 is a good primer for this purpose.

We in HEW, as a corollary feature of life cycle management, plan to conduct review and evaluation of selected systems. In addition to evaluating system performance against requirements, we intend to inspect the adequacy of system documentation to support the system, as another measure of system performance. We would expect to find documentation that approaches the FIPS PUB 38 specifications, or something reasonably adequate, in lieu thereof. Accordingly, FIPS PUB 38 will serve as a basic checklist in this review and evaluation undertaking.

To summarize, we in HEW have not legislated across-the-board-compliance with FIPS PUB 38 , but are making some progress toward its goal of better overall documentation of computer programs and automated systems. 


\section{Phillip L. Morrison \\ Office of Inspector General \\ Department of Housing and Urban Development \\ office of Audit}

4517 th Street, Si -- Room 8284

Washington, D. C. 20410

Si. ce most of you are not auditors, I would like to start by defining the role of auditors, both internal and external, in the development and evaluation of computer programs and automated systems. Then, I will address the effect documentation has on auditors, and comment on the impact I expect FIPS PUB 38 to have on auditors.

For the purpose of this discussion, I will define internal and external audit very narrowly. I define external audit as an audit group independent of the Department or Agency. Since we are dealing with the Federal Government, most external auditing is performed by the General Accounting office. I define internal audit as an audit group vithin the Department or Agency, but independent of the part of the organization responsible for the development of computer programs and automated systems.

I realize that most of the technical audits of computer programs and automated data systems are performed by audit groups within data processing organizations. I do not mean to discourage or belittle this approach, but it is part of the development process, not a totally independent review or analysis, and my talk addresses independent audits.

Since I spent almost ten years with the General Accounting office (GAO) before joining HUD, I think that I can give a fair explanation of the role of GAO. As you know, we expected to have Dr. Carl Palmer, who is currently with GAO, here with us today.

General Accounting office

GAO has been active in the area of ADP for many years, Mr. Puckorius has already mentioned GAO's involvement, and you will find a reference to the 1974 GAO Report on Documentation on the inside cover of FIPS PUB 38 . I have that report, and several other GAO reports, pamphlets, and guides dealing with ADP for any of you that may want to look at them.

One of the GAO publications that I brought is titled "STANDARDS FOR AUDIT OF GOVERNMENTAL ORGANIZATIONS, "PROGRAMS, ACTIVITIES \& FUNCTIONS." This pamphlet prescribes the standards applicable to both internal and external audits of the Government. A basic premise of these standards is that "the term audit is used to describe not only work done by accountants in examining financial reports, but also work done in reviewing (a) compliance with applicable laws and regulations, (b) efficiency and economy of operations, and (c) effectiveness in achieving program results."

Another is an exposure draft, which GAO is currently circulating for comments, "GUIDE FOR RELIABILITY ASSESSMENT OF CONTROLS IN COMPUTERIZED SYSTEMS (FINANCIAL STATEMENT AUDITS)." This draft is essentially a questionnaire, which provides auditors with a rapid, but crude, evaluation of internal controls.

I believe that a great deal of the confusion concerning the role of auditors is due to the fact that GAO has two roles. While GAO is primarily an auditing organization, it also has the responsibility to prescribe the principles and standards of accounting for the Federal Government, and to approve the accounting systems used by Federal Departments and Agencies. The GAO Manual for the Guidance of Federal Agencies prescribes both 
accounting requirements and the procedures necessary to obtain approval of an accounting system. The manual outlines some minimal documentation requirements for automated accounting systems, and refers to separate review guides which GAO uses in the approval process.

GAO has issued three review guides which agencies must complete and submit with requests for approval of accounting systems. These review guides cover the following areas:

\section{ACCOUNTING SYSTEMS DESIGN \\ ACCOUNTING SYSTEMS DESIGN: ADP APPLICATIONS \\ PAYROLL SYSTEMS DESIGN}

The review guides are, essentially, questionnaires which deal with internal controls and audit trails. An agency must answer specific questions identifying the controls in an automated system, and provide specific references to the documentation of the controls. I have copies of these questionnaires available, if any of you care to review them.

GAO approval of accounting systems is based entirely on documentation, and the review guides are used in lieu of imposing documentation standards. GAO encourages agencies to use the review guides during the design and development of automated systems that require approval. But, gAo does not start reviewing a system until the agency submits the documentation and review guides, and requests a review. This GAO review is strictly for approval purposes, and will not result in an audit report.

Most of you are probably familiar with GAO because of GAO's auditing. Since GAO auditors require compliance with the principles and standards of accounting prescribed by GAO, I can understand the common view that auditors require the inclusion of internal controls and audit trails. The distinction that I would like you to understand is that GAo does not prescribe principles and standards of accounting as part of its auditing role.

\section{Interna1 Auditors}

Internal audit organizations do not have a responsibility to prescribe principles and standards of accounting -- consequently, they do not normally prescribe any requirements for either documentation or internal controls. When internal auditors review an automated system, the primary goal is, usually, to determine if the system is performing its function accurately. This determination requires an analysis of the internal controls in the system, and controls are identified by reviewing documentation, the subject of FIPS PUB 38. A review of internal controls requires two separate determinations: (1) Did. the user identify the controls necessary to comply with applicable statutes, regulations and policies? (2) Did the ADP staff implement all of the requirements specified by the user, and all controls necessary for accurate functioning of any automated system?

If you think that you are adding controls to automated systems for auditors, you should review the purpose of the controls. The user should be far more interested in the accuracy of any automated system than the auditors. After all, auditors may look at a system occasionally or periodically, but users rely on it every day to get their job done. Users and developers must share the responsibility for the development of accurate automated systems. Auditors also have a responsibility in this area, but the audit responsibility is secondary, and it in no way diminishes the primary responsibility of the users and developers.

Ideally, internal auditors should be involved early in the development of automated systems. Mr. Puckorius stressed this in his presentation. This approach would minimize the impact of any problems auditors identify. Unfortunately, early involvement is easier said than done. Those of you who 
are auditors are aware of the difficulty involved in trying to review a system during the development process. Unless documentation is complete and current, and designed to identify internal controls, an audit of this type will require a lot of audit resources, and produce no visible product. The easy alternative for the auditors is to let the review slip until the system is developed. Then the auditors can look at finished documentation, review the GAO questionnaires, if required, and analyze the acceptance testing performed by or for the user. The auditor can use a test deck to check the functioning of the program, and he can issue a deficiency report on any problems - a product to show for his work.

The users and/or developers of automated systems could help internal auditors to review systems while they are being developed. Both of these groups know that it is easier, faster, and less expensive to design a system right in the first place, rather than to patch an operational system to make it accomplish something it was supposed to do in the first place. But, why invite trouble? How many of us would go out of our way to invite a critical evaluation of our work? Besides, the people responsible for developing systems frequently believe that auditors will place additional requirements on them, particularly in the area of internal controls. If so, it is only because others did not do their job right.

GAO and OMB have both taken a very active role in encouraging internal audit groups to evaluate automated systems while they are being developed. Two recent GAO REPORTS, one dealing with crimes in computer based systems, and the other dealing with automated decision making systems, included recommendations for internal auditors to be involved in the design, testing and operation of automated systems. Many agencies made commitments to the Congress, in response to these recommendations, and omB required all agencies to address these recommendations in their FY 1978 budget subissions. The Privacy Act has placed new requirements on automated systems, and both developers and auditors are currently evaluating their responsibilities under this act. I think it is safe to say that every audit group in the Government has either already started to get involved in the development of automated systems, or is making plans to do so.

\section{Effects of Documentation}

Poor documentation can be compared to a blindfold; this comparison is valid for both existing systems and systems under development. Poor documentation will increase the time required to perform an audit, and decrease the effectiveness of the audit.

Poor documentation will conceal some of the deficiencies in a bad system, at least for a time -- but, it will also hamper any efforts to correct deficiencies that do surface.

Good documentation is an invitation for critical analysis. If the documentation is good enough, errors will stand out like a sore thumb. But, good documentation will help the developer avoid errors and simplify the correction of errors.

Auditors can make a meaningful contribution to the development of automated systems, but only if documentation is kept current, and internal controls and audit trails are addressed adequately. Otherwise, effective audits will be feasible only after the system becomes operational. Internal audit groups are just developing the ability to review automated systems. We face real problems allocating the time of the few people who are qualified to perform this work. Unless users and developers work with us, we will be forced to delay our reviews until after the systems are implemented. This approach will let us review more systems with less resources, but it means modifying existing systems to make them do the things they should have been designed to do. As long as this continues, we will always be fighting brush fires - not an efficient or cost-effective approach for anyone. 
I have tried to show that auditors are vitally interested in both documentation and FIPS PUB 38. But, the impact is indirect, since auditors do not prepare documentation or prescribe system requirements. We use documentation, and any improvement in documentation will help auditors. I believe FIPS PUB 38 will cause a big improvement in the documentation of automated systems. The documentation required by FIPS PUB 38 does not meet al1 the needs of auditors, but it comes closer to meeting these needs than any documentation standards that $I$ have seen in any Federal Department, outside of DoD. I hope to work with HUD's standards staff in the implementation of these guidelines, and any time our auditors review a computer program or automated system we will use and evaluate the related documentation.

The documentation guidelines in this publication may meet the needs of the users and the computer professionals, but I do not think they will replace the GAO review guides. As an auditor, I would like to see the area of controls addressed separately, to assure a systematic treatment of this important area. Auditors realize that controls cost money, and the inclusion of any redundant or unnecessary controls is a waste of money. Our goal is to include the minimum number of controls necessary to achieve the required accuracy. The GAO review guides were prepared for accounting systems, where every effort must be made to avoid any errors. We recognize that this degree of accuracy is not required in all automated systems, but it is very disturbing to find that most systems are developed without a systematic approach to controls. I would like to see a systematic approach to controlling a11 input, processing and output; this would insure the placement of controls as early in the system as possible, and the avoidance of redundant controls.

My final comment on FIPS PUB 38 may not be a fair criticism, but I consider it to be a problem that these guidelines address only the automated portion of any function. When auditors review an area, they try to look at the entire operation from beginning to end, not just the automated portion. I would like to see documentation that includes an entire function, including everything that takes place before and after the automated portion. 
Fred J. Cole

Public Health Service
$\&$

Office of Education

Question:

How does one train people to document? Will Civil Service offer a course?

Young:

Training is a product of what each agency/person expects. FIPS PUB 38 does not address training. FIPS Task Group 14 has talked about having some sort of training, but nothing is planned now. While the Civil Service Commission has classes on documentation, they are not necessarily concerned with FIPS PUB 38.

Strnad:

Documentation will be prepared, with or without training, and managers must support it. Documentation has been with the ADP community since day one, so its actual needs and/or potential needs to management are well established.

Question:

Will OMB enforce FIPS PUB 38 as a standard (i.e. not a guideline)?

Reiche:

No. FIPS PUB 38 addresses all levels of document actions and therefore can be utilized as an outline of the requirements. Local management must determine the degree that FIPS PUB 38 affects any particular application. This was the logic in making it a guideline, not a standard.

Audience Comment:

Whether one uses "Standards" or "Guidelines" depends on the diversity of computer applications.

Question:

Will TG 14 assist agencies in implementing FIPS PUB 38? Are examples of documentation and forms going to be made available as guidelines?

\section{Young:}

TG 14 has no specific plans for such assistance. Examples of documentation and forms are not going to be made available. However, NASA and GSA, among others, have examples of documentation and forms which conform to the guidelines in FIPS PUB 38.

\section{Question:}

How does one "force" non-ADP professionals (e.g. mathematicians) to use FIPS PUB 38?

\section{Cole:}

Show such people how documentation is beneficial to them.

Gal1:

Enforcement is possible only in the area of security compliance. Otherwise people are "on their own hook."

Question:

Who within an organization is responsible for: (1) determining the scope of documentation, and (2) compiling the documentation?

Ga11:

(1) The project team leader in the functional area, i.e., a person not in the ADP standards area, but one who follows standards developed by the standards area. This is so whether the agency is small or large; the participation of management will depend on the complexity and size of the project. (2) The systems analyst. Some agencies have gone so far as to hire technical writers to develop the documentation required for a given system. 
Strnad:

Where there are contractors, the contracts must specify the level and complexity of documentation.

Question:

How, at the Civil Service Commission, did you get project leaders in the functional areas to take over documentation? At GPO, ADP is always taking back the function.

Ga11:

Adequate resources are provided in the functional areas. ADP does provide documentation guidelines and help.

Question:

What did Mr. Morrison mean by "controls" in non-financial systems? Are you referring to normal edit criteria, physical controls, or what?

\section{Morrison:}

The user should know his real needs, what is an acceptable product to him. Gal1:

For instance, the CSC Recruiting and Examining System has 3 million potential applicants on-line to 60 offices. System requirements specified certain privacy constraints. Auditors reviewed the system design to determine if it meets the users' requirements. Where possible, auditors are in on the development of the design specifications.

Reiche:

Auditors are concerned not just with financial management systems. Now, for example, controls are concerned with privacy.

Audience Comment:

Auditors should be looking at technical aspects of systems during development. They should be looking beyond any financial and security controls.

Audience Comment:

Auditors see themselves as providing feedback to management. Management areas looked at by auditors:

- Try to determine feasibility of the system.

- What are the objectives and how will they be met?

- Are they documented?

- Have you considered alternatives, or were you locked in?

- Have you thought about maintenance?

Technical areas looked at:

- Are there input/output controls and edit criteria?

- What is/will be the impact of the system?

- If the system goes sour, will the department be embarrassed?

- What are the risks involved?

- Security.

My Department audits on 1 y about $5 \%$ of its ADP systems.

Much discussion followed on who should have the audit function (ADP or general auditors); also, on whether auditors should have ADP training. The session ended with the following (typical) question:

Question:

operations?

Young:

The argument goes both ways, but the "new school" puts such control checks in the user area.

Gal1:

Quality control is turned back to the user. 
FIPS Task Group 14 (Documentation for Information Processing Systems) prepared FIPS PUB 38 from existing guidelines, standards, and practices in Federal agencies and other institutions. The following members of FIPS TG 14 (past and present) contributed to its development and publication.

Ruth Anderson, National Bureau of standards Fred J. Cole, Public Health Service

Phillip Diamond, Veterans Administration

C. L. Eadie, General Services Administration

Elizabeth Fong, National Bureau of Standards

James Gillespie (Task Group Chairman), Department of the Navy

D. H. Gridley, NASA Goddard Space Flight Center Robert R. Hegland, NAVCOSSACT

Helena Hood, General Services Administration

Mitchel1 Krasny, National Technical Information Service

Tom Kurihara, Department of Agriculture Edie Lasner, Office of Education

Beatrice Marron, National Bureau of Standards

Robert A. Mattes, Social Security Administration

Carl Palmer, General Accounting office

Kenneth Rodey, National Security Agency

G. Joyce Rosencranz, National Security Agency

Mark Silverman, U. S. Geological Survey

Roy A. Young, Department of Health, Education and Welfare

\section{SYMPOSIUM PLANNING COMMITTEE}

The following people were responsible for the planning and organization of the Symposium for Documentation of Computer Programs and Automated Data systems. Their plans were turned into reality by the people at NBS and CSC who earn their living by doing this sort of thing.

Mark Silverman (Chairman) U.S. Geological Survey

Roy A. Young, U.S. Department of Health, Education \& Welfare

Mitchel1 A. Krasny, National Technical Information Service

Beatrice Marron, National Bureau of Standards

Fred Rao, U.S. Civil Service Commission 


\begin{tabular}{|c|c|}
\hline U.S. DEPT. OF COMM. & 1. PUBLICATION OR REPORT NO. \\
BIBLIOGRAPHIC DATA & NBS SP-500-15 \\
SHEET & NBS
\end{tabular}

4. TITLE AND SUBTITLE

COMPUTER SCIENCE \& TECHNOLOGY:

Documentation of Computer Programs and Automated Data Systems

Proceedings of a Symposium Held at the National Bureau of St and ards, Gaithersburg, MD, October 12, 1976

7. AUTHOR(S)

Edited by Mitche11 A. Krasny

9. PERFORMING ORGANIZATION NAME AND ADDRESS
2. Gov't Accession No.

\section{NATIONAL BUREAU OF STANDARDS DEPARTMENT OF COMMERCE WASHINGTON, D.C. 20234}

12. Sponsoring Organization Name and Complete Address (Street, City, State, ZIP) Federal Information Processing Standards Task Group 14 (Documentation for Information Processing Systems), National Bureau of Standards, U. S. Department of Commerce, Washington, DC 20234

3. Recipient's Accession No.

5. Publication Date July 1977

6. Performing Organization Code

8. Performing Organ. Report No. 10. Project/Task/Work Unit No.

11. Contract/Grant No.

13. Type of Report \& Period Covered

Final

14. Sponsoring Agency Code

15. SUPPLEMENTARY NOTES

In conjunction with the ADP Management Center, U.S. Civil Service Commission, Washington, DC 20415. Library of Congress Catalog Card Number: 77-608169

16. ABSTRACT (A 200-word or less factual summary of most significant information. If document includes a significant bibliography or literature survey, mention it here.)

This symposium was organized to introduce the Government ADP-community to the concepts of when and how to apply the government-wide guidelines of FIPS PUB 38 "Guidelines for Documentation of Computer Programs and Automated Data Systems" in developing both agency standards and operational documentation. The proceedings contain all of the papers presented in the plenary session, and the papers plus summaries of question and answer sessions presented in three parallel sessions for management, operations, and staff attendees.

17. KEY WORDS (six to twelve entries; alphabetical order; capitalize only the first letter of the first key word unless a proper name; separated by semicolons)

Automated data systems; computer programs; documentation; documentation content guidelines; FIPS guidelines; software, symposium proceedings.

18. AVAILABILITY [x] Unlimited

For Official Distribution. Do Not Release to NTIS

Order From Sup. of Doc., U.S. Government Printing Office Washington, D.C. 20402, SD Cat. No.C13.70:500-15

Order From National Technical Information Service (NTIS) Springfield, Virginia 22151

\begin{tabular}{|l|c|}
\hline $\begin{array}{l}\text { 19. SECURITY CLASS } \\
\text { (THIS REPURT) }\end{array}$ & 21. NO. OF PAGES \\
UNCL ASSIFIED & 66 \\
\hline $\begin{array}{l}\text { 20. SECURITY CLASS } \\
\text { (THIS PAGE) }\end{array}$ & $\begin{array}{c}\text { 22. Price } \\
\$ 2.10\end{array}$ \\
UNCLASSIFIED & USCOMM-DC 29042.P7 \\
\hline
\end{tabular}




\section{ANNOUNCEMENT OF NEW PUBLICATIONS ON COMPUTER SCIENCE \& TECHNOLOGY}

Superintendent of Documents, Government Printing Office,

Washington, D. C. 20402

Dear Sir:

Please add my name to the announcement list of new publications to be issued in the series: National Bureau of Standards Special Publication 500-.

Name

Company

Address

City State Zip Code

(Notification key N-503) 



\section{NBS TECHNICAL PUBLICATIONS}

\section{PERIODICALS}

JOURNAL OF RESEARCH reports National Bureau of Standards research and development in physics, mathematics, and chemistry. It is published in two sections, available separately:

- Physics and Chemistry (Section A) Papers of interest primarily to scien these fields. This section covers a br cal and chemical research, wit ${ }^{2}$ standards of physical measur stants, and properties of $\mathrm{m}^{-}$ Annual subscription. Annual subscription: D 10 ! $\$ 17.00$; Foreign, $\$ 21.25$. - Mathematical Scir $8^{10}$, section B)

Studies and comr $\mathrm{m}^{8} .1 \mathrm{~s}$ designed mainly for the mathematician and on etical physicist. Topics in mathematical statis ${ }^{*}$. 10 . analysir 50 ,retical physics and chemistry, logical design in rogramming of computers and computer systr 100 nort numerical tables. Issued quarterly. Annual si scription: Domestic, \$9.00; Foreign, $\$ 11.25$.

DIMENSIONS/NBS (formerly Technical News Bulletin)-This monthly magazine is published to inform scientists, engineers, businessmen, industry, teachers, students, and consumers of the latest advances in science and technology, with primary emphasis on the work at NBS. The magazine highlights and reviews such issues as energy research, fire protection, building technology, metric conversion, pollution abatement, health and safety, and consumer product performance. In addition, it reports the results of Bureau programs in measurement standards and techniques, properties of matter and materials, engineering standards and services, instrumentation, and automatic data processing.

Annual subscription: Domestic, \$12.50; Foreign, \$15.65.

\section{NONPERIODICALS}

Monographs-Major contributions to the technical literature on various subjects related to the Bureau's scientific and technical activities.

Handbooks-Recommended codes of engineering and industrial practice (including safety codes) developed in cooperation with interested industries, professional organizations, and regulatory bodies.

Special Publications-Include proceedings of conferences sponsored by NBS, NBS annual reports, and other special publications appropriate to this grouping such as wall charts, pocket cards, and bibliographies.

A pplied Mathematics Series-Mathematical tables, manuals, and studies of special interest to physicists, engineers, chemists, biologists, mathematicians, computer programmers, and others engaged in scientific and technical work.

National Standard Reference Data Series-Provides quantitative data on the physical and chemical properties of materials, compiled from the world's literature and critically evaluated. Developed under a world-wide program coordinated by NBS. Program under authority of National Standard Data Act (Public Law 90-396).
NOTE: At present the principal publication outlet for these data is the Journal of Physical and Chemical Reference Data (JPCRD) published quarterly for NBS by the American Chemical Society (ACS) and the American Institute of Physics (AIP). Subscriptions, reprints, and supplements available from ACS, 1155 Sixteenth St. N.W., Wash. D. C. 20056.

Building Science Series-Disseminates technical information developed at the Bureau on building materials, components, systems, and whole structures. The series presents research results, test methods, and performance criteria related to the structural and environmental functions and the durability and safety characteristics of building elements and systems.

Technical Notes-Studies or reports which are complete in themselves but restrictive in their treatment of a subject. Analogous to monographs but not so comprehensive in scope or definitive in treatment of the subject area. Often serve as a vehicle for final reports of work performed at NBS under the sponsorship of other government agencies.

Voluntary Product Standards-Developed under procedures published by the Department of Commerce in Part 10, Title 15, of the Code of Federal Regulations. The purpose of the standards is to establish nationally recognized requirements for products, and to provide all concerned interests with a basis for common understanding of the characteristics of the products. NBS administers this program as a supplement to the activities of the private sector standardizing organizations.

Consumer Information Series-Practical information, based on NBS research and experience, covering areas of interest to the consumer. Easily understandable language and illustrations provide useful background knowledge for shopping in today's technological marketplace.

Order above NBS publications from: Superintendent of Documents, Government Printing Office, Washington, D.C. 20402.

Order following NBS publications-NBSIR's and FIPS from the National Technical Information Services, Springfield, $V a .22161$.

Federal Information Processing Standards Publications (FIPS PUBS) - Publications in this series collectively constitute the Federal Information Processing Standards Register. Register serves as the official source of information in the Federal Government regarding standards issued by NBS pursuant to the Federal Property and Administrative Services Act of 1949 as amended, Public Law 89-306 (79 Stat. 1127), and as implemented by Executive Order 11717 ( 38 FR 12315, dated May 11, 1973) and Part 6 of Title 15 CFR (Code of Federal Regulations).

NBS Interagency Reports (NBSIR)-A special series of interim or final reports on work performed by NBS for outside sponsors (both government and non-government). In general, initial distribution is handled by the sponsor; public distribution is by the National Technical Information Services (Springfield, Va. 22161) in paper copy or microfiche form.

\section{BIBLIOGRAPHIC SUBSCRIPTION SERVICES}

The following current-awareness and literature-survey bibliographies are issued periodically by the Bureau:

Cryogenic Data Center Current Awareness Service. A

literature survey issued biweekly. Annual subscrip-

tion: Domestic, \$25.00; Foreign, \$30.00.

Liquified Natural Gas. A literature survey issued quarterly. Annual subscription: $\$ 20.00$.
Superconducting Devices and Materials. A literature survey issued quarterly. Annual subscription: $\$ 30.00$ ! Send subscription orders and remittances for the preceding bibliographic services to National Bureau of Standards, Cryogenic Data Center (275.02) Boulder, Colorado 80302. 
